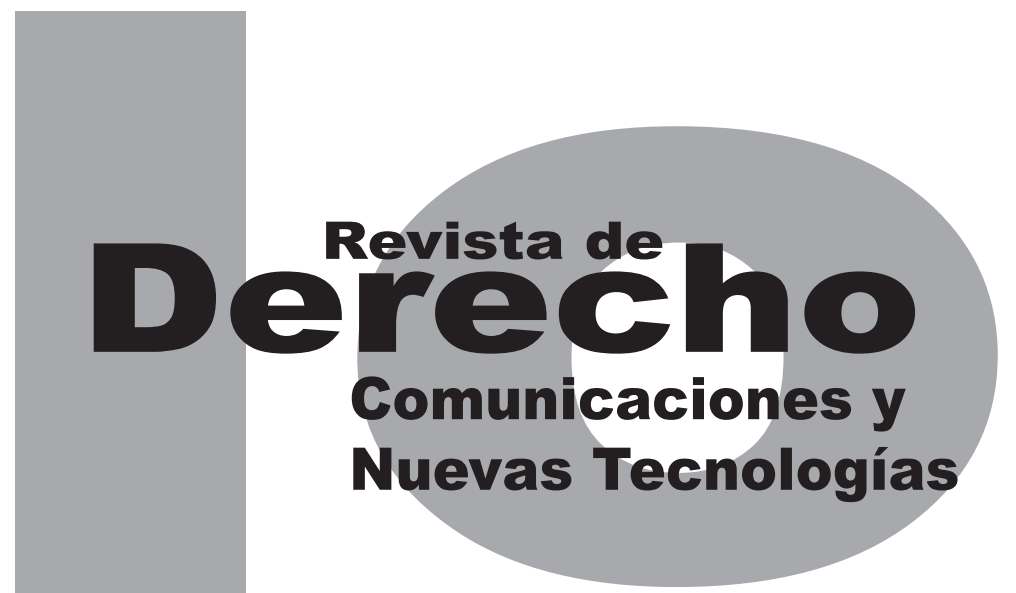

\title{
LIBERTAD DE EXPRESIÓN Y DERECHO A LA INFORMACIÓN EN LAS REDES SOCIALES EN INTERNET
}

\author{
Miguel Arrieta Zinguer
}

\section{Artículo de reflexión}

DOI: http://dx.doi.org/10.15425/redecom.12.2014.13

\author{
Universidad de los Andes \\ Facultad de Derecho
}

Revista de Derecho, Comunicaciones y Nuevas Tecnologías

No. 12, Julio - Diciembre de 2014. ISSN 1909-7786 


\section{Libertad de expresión y derecho a la información en las redes sociales en Internet}

\section{Resumen}

La libertad de expresión constituye uno de los elementos fundamentales para la existencia de la democracia, y dentro de su conformación cobra especial preponderancia el derecho a la información, que comprende a su vez un conglomerado de derechos dentro de una doble vertiente: desde el punto de vista de la capacidad de emitir informaciones, así como desde la perspectiva del derecho de los ciudadanos a recibir información sobre los temas de su interés. Su importancia deviene, por lo demás, del hecho de que constituye un derecho que facilita el ejercicio de otros derechos. El advenimiento de las nuevas tecnologías de la información y las comunicaciones ha comportado cambios relevantes en las formas como las personas perciben y difunden informaciones, lo cual ha traído un particular punto de inflexión, con la masificación del uso de las redes sociales en Internet, hoy convertidas en una de los principales formas de vinculación, comunicación y lógicamente de información interpersonal, razón por la cual se precisa analizar su importancia para el ejercicio de estos derechos comunicacionales, lo cual constituye el objetivo fundamental de la presente aproximación al tema.

Palabras clave: libertad de expresión, derecho a la información, tecnologías de la información y comunicaciones, redes sociales en Internet.

\section{Freedom of expression and right to information on social networking sites}

\section{Abstract}

Freedom of expression is one of the key element for the existence of democracy within its conformation and the right to information is essential, which in turn comprises a cluster of rights within twofold, from the point of view the ability to issue information, as well as from the perspective of the right of citizens to information on topics of interest. Its importance becomes, moreover the fact that it is a right that facilitates the exercise of other rights. The advent of new information and communication technologies have brought significant changes in the ways people perceive and disseminate information, which has brought a particular turning point, with the mass use of social networking sites, which are they have become one of the main elements through which people are connected, communicate and logically inform, reason, is required to analyze the importance that possess these elements to the exercise of these communication rights, which is the main objective of this approach to the subject.

Keywords: freedom of expression, right to information, information technologies, social networking sites.

\section{Liberdade de expressão e direito à informação nas redes sociais na internet}

\section{Resumo}

A liberdade de expressão constitui um dos elementos fundamentais para a existência da democracia e, dentro de sua conformação, cobra especial preponderância o direito à informação, que compreende a sua vez um conglomerado de direitos dentro de uma dupla vertente, desde o ponto de vista da capacidade de emitir informações, assim como desde a perspectiva do direito dos cidadãos a receber informação sobre os temas de seu interesse. Sua importância sucede já que constitui direitos que facilitam o exercício de outros direitos. O advento das novas tecnologias de informação e comunicações tem trazido mudanças relevantes nas formas de como as pessoas percebem e difundem informações, o qual implica um particular ponto de inflexão com a massificação do uso das redes sociais na internet, que tem se transformado em um dos principais elementos por meio dos quais as pessoas se vinculam, se comunicam e logicamente se informam. Por esta razão, é preciso analisar a importância que estes elementos possuem para o exercício destes direitos comunicacionais, o qual constitui o objetivo fundamental da presente aproximação ao tema.

Palavras-chave: liberdade de expressão, direito à informação, tecnologias da informação e comunicações, redes sociais na internet. 


\title{
Libertad de expresión y derecho a la información en las redes sociales en Internet*
}

\author{
Miguel Arrieta Zinguer**
}

\section{SUMARIO}

Introducción - I. LA COMUNICACIÓN COMO MANIFESTACIÓN HUMANA - II. EL DERECHO A LA INFORMACIÓN - A. Derecho a la información y su relación con la libertad de expresión - B. Derecho a la información y acceso a la información - C. Derecho a la información y privacidad - III. REDES SOCIALES Y EL EJERCICIO DEL DERECHO A LA INFORMACIÓN Y LA LIBERTAD DE EXPRESIÓN - IV. CONCLUSIÓN - Referencias.

* Cómo citar este artículo: Arrieta Zinguer, M. (Diciembre, 2014). Libertad de expresión y derecho a la información en las redes sociales en Internet. Revista de Derecho, Comunicaciones y Nuevas Tecnologías, 12. Universidad de los Andes (Colombia).

** Abogado, magíster en Gerencia de Empresas, especialista en Derecho Mercantil y en Derecho Tributario, doctorando en Ciencias Gerenciales y en Ciencias, mención Derecho. Profesor titular de la Universidad Católica del Táchira y profesor invitado en otras universidades venezolanas. Consultor Gerencial. Correo: miguelarrieta@gmail.com. 
Introducción

Las libertades comunicacionales poseen gran relevancia para el ser humano, por cuanto se vinculan particularmente con la libertad de pensamiento y el libre tránsito de las ideas, manifestación fundamental de la personalidad del individuo. De allí que, en especial en los regímenes democráticos, se tenga un especial celo por la preservación de la libertad de expresión, como derecho indispensable para la existencia y respeto de los derechos humanos en general, el respeto de la diversidad, el valor de las opiniones, etc. Las redes sociales en Internet (RSI) han cobrado una relevancia inusitada en el mundo actual en virtud del éxito indudable que han tenido como plataforma de vinculación y comunicación entre las personas mediante el uso de las tecnologías de la información y la comunicación (TIC). Por ello conviene ponderar su valor desde el punto de vista del ejercicio de los derechos comunicacionales respecto de las informaciones, opiniones e ideas que circulan por ellas, así como las circunstancias que se derivan de su uso abusivo. El presente artículo busca analizar la vinculación entre el ejercicio de las libertades y derechos comunicacionales, desde la perspectiva de la utilización de las RSI, y las diversas modalidades y vertientes que estas generan en la actualidad.

\section{LA COMUNICACIÓN COMO MANIFESTACIÓN HUMANA}

La comunicación responde a la necesidad natural del hombre de expresar sus ideas, necesida- des e intereses, lo cual es inherente no solo a su condición de ser social sino a su desarrollo y constante evolución, que por lo demás refleja la producción cultural del pensamiento humano. En tal sentido, José Julio Fernández (2002), estima que "La comunicación crea todo un proceso de significación que engloba a la cultura generando un contexto en el que se produce la interacción humana y la influencia en las propias pautas de comportamiento individual y colectivo en términos, en gran parte, de socialización" ( $p$. 297). De hecho la comunicación es una manifestación de la necesidad de interactuar con los congéneres para construir las interrelaciones propias de un ser social inteligente.

Eduardo Novoa Monreal considera que "El intercambio de ideas, opiniones e informaciones permite que cada ser humano pueda aprovechar para sí lo que aportan la inteligencia, la experiencia y el conocimiento de los demás" (2001, p. 138). La comunicación entre los hombres crea, en consecuencia, el ambiente que permite que cada uno crezca en la riqueza de sus pensamientos y conocimientos mediante el intercambio de ellos con otros hombres. Por otra parte, puede ponderarse la comunicación como un derecho individual y colectivo, toda vez que responde a una necesidad humana básica, que inserta al individuo en la sociedad. ${ }^{1}$ Debe

\footnotetext{
1 El derecho a la comunicación ha sido establecido por la Constitución de la República Bolivariana de Venezuela (CNRBV), en su artículo 58, en los siguientes términos: "La comunicación es libre y plural y comporta los deberes y responsabilidades que indique la ley. Toda persona tiene derecho a la información oportuna, veraz e imparcial, sin censura, de acuerdo con los principios de esta Constitución, así como a la réplica y rectificación cuando se vea afectada directamente por informaciones inexactas o agraviantes. Los niños, niñas y adolescentes tienen derecho a recibir información adecuada para su desarrollo integral."
} 
precisarse además, que "la noción del derecho a la comunicación guarda estrecha relación con la esfera de los valores sociales y culturales, y a medida que se reconoce y fomenta una pluralidad de valores es inevitable que aparezcan diversos puntos de vista" (Unesco, 1976). De manera que la comunicación resulta un valor esencial dentro del desarrollo cultural de los pueblos, al representar la esfera de valores y creación intelectual de las personas, al expresar las opiniones, pareceres y divergencias que pueden surgir entre los seres humanos.

La comunicación debe entenderse como el género, del cual la información constituye la especie, pues dentro de aquella caben además las manifestaciones artísticas, las comunicaciones telemáticas, la educación y también la información (Novoa, 2001, pp. 136-141), mientras que la información constituye la especie, esto es, la comunicación de hechos ocurridos y opiniones generadas a raíz de los primeros. La comunicación es, pues, la que constituye el presupuesto de la información, y la información la que permite el elemento básico para la formación de la opinión pública y el ejercicio de la libertad de expresión.

Conforme al régimen constitucional venezolano, la comunicación como derecho posee una amplia vinculación con la libertad de expresión, que implica a su vez la prohibición de censura, en general; no obstante, el derecho de informar conlleva las responsabilidades que pudiesen generarse en caso de emitir informaciones que generen perjuicios morales, o que resulten inexactas. Por otra parte, se establece el dere- cho de los menores de edad a recibir informaciones adecuadas. Este marco conceptual ha sido desarrollado ampliamente a nivel normativo en los últimos años, por cuanto la Ley Orgánica de Telecomunicaciones establece (i) el desarrollo del derecho a la comunicación, cuando esta se expresa mediante la utilización de elementos radioeléctricos, electromagnéticos, etc.; y (ii) el derecho a que la comunicación sea libre y plural, lo cual se manifiesta en la posibilidad de establecer radioemisoras y televisoras comunitarias de servicio público, sin fines de lucro. Por su parte, la responsabilidad que se deriva del ejercicio de la labor comunicativa e informativa también está regulada por la Ley de Responsabilidad Social en Radio, Televisión y Medios Electrónicos (LRSRTVME), que determina las normas, límites y sanciones a las personas que se dedican a la labor informativa y comunicativa, cuando realizan dichas actividades a través de medios radioeléctricos (radio y televisión de señal abierta, servicios de difusión por suscripción y medios electrónicos).

Hoy en día, el ejercicio de la comunicación comprende tanto la expresión escrita como la oral e incluso telecomunicacional, por cuanto el desarrollo de las nuevas TIC ha permitido el advenimiento de nuevos medios para el ejercicio de este derecho humano fundamental, particularmente a partir del desarrollo intenso que han tenido las telecomunicaciones en las últimas décadas. En lo tecnológico, se ha venido operando la integración de redes y sistemas a través de la interconectividad y la interoperabilidad, dando paso a la denominada globalización, cuyo ejemplo más palpable y evidente es el desarrollo y 
crecimiento de la red mundial de informática conocida como Internet.

La comunicación, tal y como se dijo anteriormente, responde a una necesidad esencial del ser humano, que lo ha enfrentado incluso a vencer las distancias para llegar con sus mensajes más allá de la frontera de lo inmediato creando los medios para desarrollar esa manifestación natural, naciendo así los medios de comunicación en su gran diversidad, los cuales han venido evolucionando a la par de la tecnología. De hecho, autores de tanta significación como Manuel Castells han analizado el desarrollo tecnológico de la comunicación, desde la perspectiva de la evolución del pensamiento y modos de percibir la información, haciendo un paralelismo con el desarrollo de la imprenta, que modificó 3000 años de tradición oral desde el momento en que lo hablado se comenzó a transcribir y traspasar a un lenguaje y simbología escrita. Dicho desarrollo es igualmente ponderado desde el punto de vista de la sociedad de la información, donde el avance de la cultura multimedia, caracterizada por la intensa diversidad de medios y formas de presentación de la información, confluye en una nueva forma de pensar y representar simbólicamente el pensamiento, más allá del lenguaje puramente escrito, en una interacción dinámica del pensamiento simbólico multidimensional.

En esta evolución constante, a lo largo de los años, se puso de manifiesto la transformación de la comunicación en sus diversas dimensiones entre los seres humanos, la cual fue manifiesta durante el siglo pasado con la irrupción de los medios radioeléctricos que permitieron llevar los mensajes hacia nuevos derroteros y al mismo tiempo abrieron el camino a nuevas formas de aprender y de obtener información, así como de comunicarse. Señala Manuel Castells que la "tensión entre la comunicación alfabética noble y la comunicación sensorial e irreflexiva subyace en la frustración de los intelectuales opuestos a la influencia de la televisión, que sigue dominando la crítica social de los medios de comunicación de masas" (2006, p. 360). Ahora bien, si esto lo traslapamos al desarrollo reciente y crucial de la Internet, que permite el desarrollo y comunicación interactiva de textos contentivos de ideas y pensamientos, con música, video, imágenes, colores sugestivos, etc., no cabe duda que esto determina cambios culturales importantes, en cuanto a la concepción, instantaneidad e interacción de la comunicación entre los seres humanos. ${ }^{2}$

Las transformaciones que se han venido produciendo en los medios de comunicación, como consecuencia de las modificaciones y evoluciones propias del desarrollo e interacción de nuevas tecnologías de la comunicación, así como de la convergencia tecnológica entre los medios, y particularmente por la irrupción de las tecnologías de redes abiertas, han traído como consecuencia que los distintos medios tengan nece-

2 Esta interacción tiene una trascendencia esencial, por cuanto por una parte significa un elemento difusor de la cultura y de la información, pero por otra parte representa la interacción de los seres humanos en un contexto global, que fue previsto en su concepción integradora y al mismo tiempo descentralizadora por McLuhan, quien revolucionó el pensamiento acerca de la comunicación en un proceso que en mi concepto comprende la evolución desde lo que denomino 'de la galaxia Gutemberg a la galaxia McLuhan', para describir precisamente ese tránsito desde la comunicación propia de la palabra escrita, hasta la difusión global del pensamiento mediante el uso de los medios radioeléctricos. 
sidad de transformarse. Así, los periódicos que originalmente solo se imprimían sobre soporte papel, comenzaron a integrarse con la Internet, generando una nueva consideración acerca de su valor e importancia, dada la nueva estimación del poder multimediático que ofrece la red global, al punto de dar vida a un nuevo medio interactivo, que no solo es un periódico en la red, sino uno que precisa valores agregados capaces de atraer y mantener el interés del público consumidor. Estas consideraciones no solo se aplican a los medios impresos en su interacción con la Internet, sino a todos los demás, incluso los televisivos y radiales, puesto que las TIC (particularmente en cuanto al desarrollo de los estándares de televisión digital y radio digital), cambiarán profundamente la conformación de todos ellos a la vez que permitirán la ampliación significativa del volumen en cualquier parte del mundo donde haya un público sediento de información, que podrá acceder a sus contenidos desde la comodidad de sus casas, con un simple dispositivo que le brinde conexión a la Internet.

Ahora bien, las transformaciones que la comunicación ha tenido desde el advenimiento de Internet se han visto, por lo demás, impactadas por un fenómeno esencial en cuanto a la forma en que los seres humanos establecen vínculos y se informan: la masificación del uso de las RSI como manifestación concreta de la sociedad de la información.

\section{EL DERECHO A LA INFORMACIÓN}

El derecho a la información se ha convertido en un derecho inalienable para cualquier ciudadano, y se sitúa dentro de los derechos civiles y políticos reconocidos en cualquier parte del mundo, aunque existe la tendencia por parte de algunas organizaciones, con la Unesco a la cabeza, de ubicarlo dentro de los derechos culturales. Este derecho constituye, por tanto, un pilar de la convivencia democrática, y al tiempo un derecho fundamental del individuo. Ha sido calificado como un derecho humano de primera generación, vale decir, los derechos civiles y políticos que tienen por finalidad la protección de la libertad, la integridad física y moral de los seres humanos.

El derecho a la información se reputa como un 'derecho de doble vía', ${ }^{3}$ en el sentido de esa doble vertiente que significa recibir y dar información, pero está claro que su núcleo operacional está representado por la posibilidad de buscar, recibir y difundir información, que según Urbina Serjant (2006, pp. 17-20), constituye 'el derecho genérico a la libertad de información'. De manera que todo ser humano, tanto de manera individual como colectiva, tiene el derecho de buscar información para obtener un conocimiento cabal de los hechos, ideas y sucesos que le atañen, con el objeto de poder formar con verdadera libertad su opinión; pero también a recibir la información que resulte relevante para tomar posición sobre los asuntos que le afecten.

3 Así lo ha declarado la Corte Constitucional colombiana, Sala Tercera de Revisión, en la sentencia T-512, del 09-09-1992. 
El derecho en análisis comprende a su vez un conjunto de derechos y facultades que varían en su consideración y contenido. En general se considera que está integrado básicamente por tres facultades: investigar, recibir y difundir mensajes informativos. La facultad de recibir implica la obtención y recepción de información, de acuerdo con los propios intereses, mientras que la facultad de investigar la poseen tanto los profesionales de la información como el públi$c o, y$ les permite acceder a las fuentes de información y de opinión, sin limitaciones, siendo un deber para quienes manejan las fuentes de información permitirles el acceso. NogueiraAlcalá (2000, pp. 21-22) opina que el derecho a la información es un complejo de derechos que guardan relación tanto con respecto al que informa (informador) como a quien percibe la información (informado), difiriendo en cada caso en cuanto a los derechos que lo conforman; así:

\section{A) En relación con el informador, se encuentran}

los derechos a: i) Investigar y buscar informaciones y opiniones; ${ }^{4}$ ii) Difundir informaciones de relevancia pública por cualquier medio y opiniones; iii) Emitir informaciones u opiniones; 5 iv) No

4 En la obtención de la información, el profesional de la información (periodista, reportero), o la persona normal, tiene derecho de realizar los contactos, entrevistas, que estime convenientes, con la condición de que dicha información vaya dirigida al público. Según Escobar de la Serna (1998) el derecho a la información debe entenderse como "la facultad atribuida a los profesionales de la información, a los medios informativos en general y al público, de acceder directamente a las fuentes de las informaciones y de las opiniones y de obtener éstas sin límite general alguno, facultad que debe considerarse en su doble faceta, es decir, como derecho del ciudadano y como deber de los que manejan las fuentes de información" (p. 57).

5 La garantía que permite la existencia de información verdaderamente libre, precisa que la legislación del país de que se trate garantice la confidencialidad de la fuente y el secreto profesional del periodista; el cual se debe acompañar de una normativa profesional adecuada en cuanto a la ética profesional, así como un manejo legítimo de la información, de tal suerte que no afecte ilegítimamente la honra o reputación de las personas. ser censurado, ${ }^{6}$ ni objeto de restricciones preventivas en forma explícita o implícita, directa o indirecta, a excepción de medidas destinadas a proteger la moral de los menores o adolescentes, o en casos de estados de excepción consti-

La libre difusión de las ideas tiene como límite la confidencialidad para las personas naturales o jurídicas.

6 Con respecto a la prohibición de censura conviene precisar que el artículo 13.2 de la Ley Aprobatoria de la Convención Americana de Derechos Humanos establece límites a la libertad de expresión o de pensamiento, contemplando responsabilidades ulteriores a la expresión, que comprenden específicamente que el ejercicio del derecho a la libertad de expresión: "no puede estar sujeto a previa censura sino a responsabilidades ulteriores, las que deben estar expresamente fijadas por la ley y ser necesarias para asegurar: a) el respeto a los derechos o a la reputación de los demás, o b) la protección de la seguridad nacional, el orden público o la salud o la moral pública. 3. No se puede restringir el derecho de expresión por vías o medios indirectos, tales como el abuso de controles oficiales o particulares de papel para periódicos, de frecuencias radioeléctricas, o de enseres y aparatos usados en la difusión de información o por cualesquiera otros medios encaminados a impedir la comunicación y la circulación de ideas y opiniones. 4. Los espectáculos públicos pueden ser sometidos por la ley a censura previa con el exclusivo objeto de regular el acceso a ellos para la protección moral de la infancia y la adolescencia, sin perjuicio de lo establecido en el inciso 2. 5. Estará prohibida por la ley toda propaganda a favor de la guerra y toda apología del odio nacional, racial o religioso que constituyan incitaciones a la violencia o cualquier persona o grupo de personas, por ningún motivo, inclusive los de raza, color, religión, idioma u origen nacional." Por su parte, el Tribunal Supremo de Justicia de Venezuela, en Sala Constitucional, en su sentencia n. 1942 pareciera legitimar la posibilidad de la censura previa, en ciertas ocasiones, al establecer lo siguiente: "A juicio de esta Sala, el artículo 13.2 colide en cierta forma con el artículo 57 constitucional. Este prohíbe la censura a las expresiones que se difundirán por los medios de comunicación o difusión, lo que es coincidente con la letra del artículo 13.2 comentado, pero el artículo 57 constitucional no permite el anonimato, ni la propaganda de guerra, ni los mensajes discriminatorios, ni los que promuevan la intolerancia religiosa, sin diferenciar, al no prohibirla, en qué oportunidad se impedirá su difusión. Como el artículo 58 constitucional se refiere a la comunicación de la expresión e información "sin censura, de acuerdo a los principios de esta Constitución", la Sala interpreta que en materia comunicacional y por aplicación de otros principios constitucionales, la ley puede impedir la difusión de informaciones que dejen sin contenidos otras normas constitucionales o los principios que rigen la Carta Fundamental. A juicio de la Sala, ello puede tener lugar aun antes de que los medios de comunicación lo hagan conocer, ya que, de no ser así, el efecto nocivo, que reconoce la norma constitucional y que trata de impedir, tendría lugar irremisiblemente... Para que no se permitan tales expresiones, la ley puede crear censura previa a su difusión o comunicación, siempre que actos jurisdiccionales la ordenen. Sin embargo, las prohibiciones del artículo 57 constitucional son en parte distintas de aquellas que el artículo 13 de la Convención Americana sobre Derechos Humanos contempla, las cuales nunca pueden ser objeto de censura anterior a su difusión o comunicación, pero que sí generan responsabilidades (de acuerdo con lo que establece la ley) a quien las exprese en cualquier forma. Apunta la Sala que son en parte distintas, ya que hay supuestos contemplados en ambas normas, las cuales al ser diferentes, otorgan efectos distintos a los supuestos coincidentes. 
tucional; v) Acceso a las fuentes de información; ${ }^{7}$ vi) Secreto profesional periodístico y a la reserva de las fuentes; ${ }^{8}$ vii) La cláusula de conciencia; 9 viii) Al acceso y utilización de los instrumentos y medios naturales o tecnológicos necesarios que permitan emitir las opiniones e informaciones.

B) Por lo que respecta al informado, comprende los derechos a: i) Recibir opiniones e informaciones; ii) Seleccionar la información que recibe y los medios a través de la cual recibirla; iii) Ser informado veraz y oportunamente; iv) Que sea preservada su honra y vida privada; v) Rectifi-

7 Esto determina la obligación para los Estados de no efectuar actuaciones destinadas a evitar o limitar la libre recepción de la información de carácter público, así como promover condiciones que permitan el libre ejercicio de la obtención de la información, de modo que el ordenamiento jurídico debe establecer la obligación de las autoridades gubernamentales de entregar la información sobre todo asunto público de relevancia para la población, con excepción de la información reservada por ley.

8 El derecho al acceso a la información pública supone el derecho de inquirir acerca del origen de los datos almacenados, por lo que cobra relevancia respecto de la reserva de la fuente de información, que se puede utilizar para limitar la facultad indagatoria, a la que se contrapone también la negativa de informar en determinados casos, fundada en el deber de secreto acerca de la fuente de información, que comprende uno de los elementos fundamentales dentro del secreto profesional, propio del ejercicio de la función de periodista. De hecho, el secreto profesional del periodista se concibe como un derecho subjetivo de naturaleza pública que integra la libertad institucional de la prensa. Entonces queda claro que las fuentes de información de los periodistas son secretas por mandato constitucional (artículo 28 de la Carta Fundamental venezolana) y legal (artículo 8 de la Ley de Ejercicio del Periodismo). En consecuencia, cualquier tipo de exceso por parte de los periodistas, que atente contra el derecho de los demás y contra el artículo 58 constitucional, generaría responsabilidades legales de los editores o de quienes los publican, al no tener la víctima acceso a la fuente de la noticia que lo agravia. Pero además de estas acciones, y sin que sean excluyentes, las personas tienen el derecho de réplica y rectificación cuando se vean afectadas por informaciones inexactas o agraviantes.

9 Se encuentra representada por aquellas cláusulas legales que se consideran implícitas en los contratos de trabajo con los periodistas, conforme la cual, en los supuestos en que la ley tipifica en relación con la conciencia del informador, los efectos económicos de la extinción de la relación laboral periodística producidos por voluntad unilateral del trabajador, equivalen a los de despido por voluntad del empleador. De modo que la cláusula de conciencia busca salvaguardar la libertad ideológica, el derecho a expresar libremente la opinión y la ética profesional del periodista, concebida como elemento de la libertad de expresión, como elemento conformante del derecho a la información. cación o respuesta; ${ }^{10}$ vi) Solicitar la imposición judicial de responsabilidades civiles y penales en los casos determinados por el ordenamiento jurídico.

Con respecto al carácter e importancia de este derecho, Escobar de la Serna, señala que:

actúa sobre una realidad viva, a la que regula y ordena, que son los medios y cuanto éstos se configuran en su entorno. Pero estamos en la era en la que los medios constituyen una figura central de la vida social y política de los ciudadanos. De modo que el nacimiento del concepto "mediocracia" se convierte en el indicador terminológico del cambio dramático que ha experimentado la relación entre ciertos valores como la política, y los medios de comunicación a lo largo de las últimas décadas. Las instituciones de la comunicación de masas, que hasta la mitad de este siglo apenas eran mencionadas en los tratados sobre sistemas políticos, se han convertido hoy para algunos autores en elementos constitutivos de los sistemas democráticos. De modo que la política y el consenso político, como otras relaciones de carácter social, se establecen principalmente

10 En cuanto al derecho a la réplica, este corresponde únicamente a las personas que son agraviadas o afectadas por informaciones incorrectas, mas no a los periodistas o medios de comunicación; en efecto, la sentencia 1013 del Tribunal Supremo de Justicia de Venezuela ha sentado que: "el derecho a la réplica y a la rectificación no lo tienen ni los medios, ni quienes habitualmente ejercen en ellos el periodismo, ni quienes mantienen en ellos columnas o programas, ni quienes mediante "remitidos" suscitan una reacción en contra. Se trata de un derecho concedido a quienes se ven afectados por la información de los medios, y que carecen de canales públicos para contestar o dar su versión de la noticia. Quien publica un remitido en un medio, si un interesado le contesta en otro medio, no puede pretender (quien publicó el primero) le den gratis un espacio en el segundo medio para contrarreplicar, ya que los remitidos no forman parte del periodismo de información al cual se refiere el artículo 58 comentado; pero tampoco pueden los periodistas, directores y editores de medios de comunicación, pretender que en otro medio se les permita responder lo que en él se haya difundido y consideren los perjudica, ya que estarían utilizando innecesariamente un espacio, cuando muy bien ellos, utilizando sus canales de difusión escritos, orales o audiovisuales, pueden hacerlo." 
en y a través de los medios de comunicación, lo cuales ejercen también una influencia directa sobre los acontecimientos políticos y la opinión de la población a través de la comprensión periodística de los roles y de los criterios en la selección de noticias (1998, p. 34).

De manera que el derecho de la información incide sobre la realidad social, de la cual proviene, puesto que interactúa con los hechos cotidianos que constituyen el insumo fundamental de los medios de comunicación, que en su importancia e interacción con la sociedad misma influyen en los procesos sociales y políticos de las sociedades contemporáneas, constituyendo una fuerza que en muchos casos moldea, a la vez que es reflejo de dichas sociedades. Son un elemento determinante en la conformación de la democracia tal y como la entendemos en la actualidad, por cuanto implican la necesidad de configurar la opinión pública, así como la transparencia necesaria en el ejercicio de la función pública, que es sometida a constante escrutinio por parte de la sociedad, sirviendo los medios de comunicación como elemento intermediario entre estos factores.

\section{A. Derecho a la Información y su relación con la libertad de expresión}

El derecho a la libertad de expresión fue instituido en la Declaración de los Derechos del Hombre y del Ciudadano de 1789, pero se convirtió en un derecho realmente reconocido con carácter universal como derecho a la información en 1948, en la Declaración Universal de Derechos Humanos al establecer: todo individuo tiene derecho a la libertad de opinión y de expresión; este derecho incluye el de no ser molestado a causa de sus opiniones, el de investigar y recibir informaciones y opiniones y el de difundirlas, sin limitación de fronteras, por cualquier medio de expresión.

Constituye entonces un derecho humano inalienable, al tiempo que un derecho social indispensable. Comprende, según Escobar de la Serna (1998), la facultad de recepción y difusión de noticias, derecho que exige unas condiciones, la primera de las cuales es la verdad. Las noticias deben referirse a información relevante, incluyendo la política, y ser conformes con la realidad, exigiendo una completa independencia por parte del informador. Las opiniones comprenden las ideologías, juicios u opiniones propiamente dichas, o conclusiones que se obtienen de aplicar las ideas a los hechos.

Las libertades de información y expresión son derechos usualmente consagrados en las constituciones democráticas dentro de los derechos fundamentales. Constituyen presupuestos básicos para el sistema de convivencia democrática, y son herederas de la libertad de imprenta, aplicables en Venezuela desde las Leyes de Indias, y consagradas en 1812 en la Constitución de Cadiz. La doctrina suele referirse a la libertad de expresión ${ }^{11}$ cuyo objeto estaría dado por la emisión de ideas, opiniones y juicios, en tanto que la libertad de información anidaría en la publi-

\footnotetext{
11 Según Faúndez (2004), "la libertad de expresión es un derecho de todos, aun cuando su ejercicio está estrechamente relacionado con los medios de comunicación; lo que hace la prensa es constituirse en un canal de comunicación para que distintos sectores sociales expresen públicamente sus aspiraciones, temores y esperanzas. No se puede ignorar que, en el mundo de hoy, es precisamente a través de los medios de comunicación que recibimos la mayor parte de la información" (pp. 17-18).
} 
cación o divulgación de hechos o noticias (información en sentido estricto). A esta posición dualista se le opone la unitaria que unifica ambas libertades, si bien con distintas dimensiones. Ahora bien, algunos autores consideran que la libertad de expresión y de información constituyen derechos distintos, puesto que la libertad de expresión tiene por objeto la capacidad de poder manifestar cualquier concepción intelectual (ideas, creencias, pensamientos, opiniones, etc.), por cualquier medio, constituyendo una manifestación de la libertad de opinión; mientras que la libertad de información supone la existencia de un derecho a una comunicación libre, que comprende el derecho a emitir información y otra a ser informado.

Refiere Urbina Serjant (2006, pp. 42-45), que en el proceso constituyente del año 1999, al discutir el tema referente a la libertad de expresión, así como en la mayor parte de las constituciones de América Latina, se tomó el concepto de 'información veraz', proveniente del artículo 20 de la Constitución Española de 1978, y conforme al cual los derechos a la libertad de expresión y a la libertad de información se comprenden 'de forma interdependiente', pero no bajo la premisa de que al reconocerse el primero, se garantizaba el segundo. De hecho, el autor señalado, considera que

La influencia de la constitución española sobre la doctrina del Derecho de la Información se evidencia en el dato corroborable de que, después de promulgada, en la teoría y la práctica jurídicas hay reservas importantes frente a la homologación de los derechos a la libertad de expresión y a la libertad de información (2006, p. 44).
De manera que la libertad de información se distingue de la expresión, de acuerdo con este criterio, en la necesidad de que se trate de hechos noticiables, así como de la inclusión del concepto de veracidad de la información; de modo que si bien anteriormente se englobaban dentro del concepto de libertad de expresión, no cabe duda que la tendencia actual es a escindir, dentro de los derechos comunicacionales, la libertad de expresión de la libertad de comunicación.

Además se precisa, en buena parte de los sistemas jurídicos, que la información sea 'veraz' (por ejemplo, en Venezuela, art. 58 de la Constitución), lo cual no comprende necesariamente la obligación de que la información sea cierta, sino que haya sido obtenida de manera diligente, contrastando los hechos con los datos objetivos, de modo que de existir alguna inexactitud, no estará motivada por la negligencia de la persona que informa. Ahora bien, en caso que la información no sea veraz, se debe distinguir la información errónea de la falsa, puesto que esta última genera responsabilidad penal y civil, mientras que la primera podría generar responsabilidad civil, solamente en el caso que la persona que difunde esta información no haya utilizado adecuada diligencia para evitar perjuicios, actuando de mala fe..$^{12}$

No cabe duda acerca de la trascendencia esencial de la libertad de expresión dentro de cualquier régimen de libertades, y particu-

12 Para determinar la responsabilidad civil o penal, se precisa probar fehacientemente la falsedad del contenido de lo informado, así como contar con prueba de que la persona que emite la información conocía la falsedad de la noticia, así como su negligencia para contrastar o investigar acerca de la veracidad de la materia informada. 
larmente para los Estados democráticos. No obstante, la libertad de informar comporta lógicamente el cumplimiento de deberes relativos a la responsabilidad social, y a la responsabilidad ulterior por las opiniones vertidas en los medios de comunicación, sin que pueda existir la censura previa. ${ }^{13}$ Ahora bien, es un hecho que los medios de comunicación deban cumplir con responsabilidades derivadas de su función, así como las finalidades de responsabilidad social constituyen contrapartidas lógicas de la libertad de que deben gozar en los regímenes de corte democrático. No obstante, deben también los medios optimizar la calidad intrínseca de los contenidos que emiten. ${ }^{14} \mathrm{La}$ función democrática de la libertad de información es especialmente intensa, puesto que la televisión no solo es un medio de información, sino un factor fundamental para la formación de la opinión pública, aparte de constituir el principal medio de información y distracción de la ciudadanía. ${ }^{15}$ De allí que se ha considerado

13 Chavero (2006), con respecto a la importancia de la libertad de expresión, indica que: "A pesar de que a veces se afirme con suelta ligereza que este papel protagónico de la libertad de expresión se debe a la afectación de los intereses económicos de los propietarios de los medios de comunicación -lo que no descartamos por completo-, consideramos que la discusión de los asuntos relacionados con este derecho fundamental es un tema de Estado, y a la vez es un asunto que interesa a todos los ciudadanos, pues de ello no sólo depende una de las garantías más elementales del ser humano (libre expresión del pensamiento), sino también la forma de gobierno más aceptada de nuestros tiempos, la democracia" (p. 27).

14 En tal sentido, Escobar de la Serna (1998, p. 87), considera que: "Quizá la respuesta esté no sólo en el hecho de que los medios respondan en sus contenidos a una ética y a un grado máximo de calidad intrínseca, sino en el uso que el individuo haga de aquéllos pues en una gran medida el defecto no está en el medio en sí sino en el mal uso o el abuso que de él se hace, olvidando lo que Erich Weber ha denominado la "educación para una renuncia práctica", para evitar la exposición indebida, excesiva o arbitraria a los medios de comunicación; ello nos llevará sin duda de la mano a un mejor entendimiento y a una más adecuada utilización y provecho de ese fenómeno tan actual y tan imprescindible que es la comunicación política y su relación ineludible y estrecha con la opinión pública libremente formada y expresada."

15 La televisión, por lo demás, tiene una especial fuerza sugestiva en los espectadores, al presentar los hechos y sucesos como reales. No es lo mismo leer o escuchar, que ver y escuchar al mismo tiempo; de allí deriva que los medios de comunicación audiovisual deben obedecer a ciertos parámetros que permitan cumplir con su finalidad, sin sacrificar la libertad de expresión e información, ${ }^{16}$ pero garantizando al mismo tiempo las obligaciones de divulgación social, la protección de los valores democráticos y la protección de los niños y adolescentes, obligaciones disciplinadas en Venezuela en la LRSRTVME.

Ahora bien, en cuanto a la consideración de la Internet como nuevo ámbito para la comunicación, Teruel (2011) estima que constituye:

un nuevo espacio para el desarrollo de las libertades públicas, y, entre todas ellas, la libertad de expresión es su reina. En este sentido, el Juez Dalzell definía este medio como una conversación sin fin a lo largo y ancho del planeta. En definitiva, Internet es hoy día la - plaza pública, el -ágora de la comunidad global. Un espacio a través del cual la comunicación salva cualquier género de impedimento espacial o temporal; que abre las puertas a un nuevo modelo comunicativo multidireccional y totalmente horizontal, disperso y descentralizado, interactivo, y con una profunda vocación democratizadora (pp. 53-54).

En consideración del significativo ámbito de acción que determina Internet como espacio para el intercambio de información, de donde resalta

\footnotetext{
su significativa influencia. De allí que en algunos países se ha declarado a los servicios de televisión como privativos del Estado (servicios públicos generales).
}

16 La legitimidad en la intervención del Estado en la libertad de programación se ha fundamentado en la necesidad de "asegurar el pluralismo en el uso de la libertad de información" (sentencia del Tribunal Constitucional español). La libertad de programación se integra en el ámbito protegido de la libertad de comunicación y tiene una dimensión negativa en la prohibición de establecimiento de injerencias estatales o particulares que incidan en dicha libertad. 
su importancia para la libertad de expresión, ${ }^{17}$ conviene precisar que no en todos los supuestos en que se publiquen contenidos en Internet se afectan necesariamente las libertades comunicativas, aunque concibamos la libertad de expresión como la facultad que tiene el ciudadano tanto de recibir como de difundir y recibir mensajes, informaciones, ideas, abstracción hecha del medio empleado para su comunicación. Ahora bien, si consideramos que Internet ${ }^{18}$ no solo funciona como una red de comunicación, sino que también tiene un sitial preponderante en la realización de todo tipo de operaciones y la prestación de servicios de variada naturaleza, entendemos por qué debe valorarse y cuáles son aquellos casos en los que pueda verse comprometido el ejercicio de la libertad de expresión; siendo necesario determinar en cada caso a qué se dedica cada página web en particular y cuál es el carácter y valor de la información y difusión

17 Pedro Grimalt (2010, p. 270) afirma: "Personalmente no creo que Internet aporte nada especial al contenido esencial de las libertades de información y de expresión, aunque sí al modo de ejercitar dichas libertades. Comento esto porque se ha estado haciendo mucho hincapié en que Internet nos obliga a revisar el contenido de la libertad de expresión y de información y así estas libertades también deberían amparar a los ciudadanos y no sólo a la llamada prensa, o se está afirmando que la libertad de expresión o de información debe ir más allá que proteger informaciones de relevancia pública o que afecten a personas públicas, pues los ciudadanos deben poder expresar sus ideas, sus inquietudes, dar información de cualquier cosa, al margen de su relevancia pública."

18 Se debe precisar que el concepto de Web 2.0 surgió de una sesión de brainstorming realizada entre O'Reilly y MediaLive Internacional, y fue acuñada por el primero en 2004 para referirse a una "segunda generación" de Internet caracterizada por ofrecer aplicaciones que facilitan a los usuarios la generación de contenidos, dentro de una red colaborativa, que permite el almacenaje de datos y aplicaciones en servidores Web y el acceso a los mismos con un navegador. De esta manera, la comunicación se vuelve bidireccional y dinámica y son los usuarios, mediante sus aplicaciones y su interactuación en las redes, quienes eligen los temas de interés y los que marcan el camino a seguir en un ámbito concreto del conocimiento (Rubio, 2011, p. 152). de ideas, así como la importancia económica, según el tipo de actividad a la que se dedique. ${ }^{19}$

\section{B. Derecho a la información y acceso a la información}

\author{
La libertad de información ${ }^{20}$ tiene una manifes- \\ tación específica importante en el derecho al
}

19 Teruel (2011) considera que "Se deberán distinguir aquellas páginas dedicadas a la difusión de informaciónll32 —entendiendo información en su sentido más amplio y con independencia que tal actividad represente de manera directa o indirecta un beneficio económico o suponga en sí misma ejercicio de actividad económica-, que sí que supondrían un ejercicio de la libertad de expresión; y, por otro, esas otras páginas web que se dedican a la — prestación de servicios telemáticosll -en general-, los cuales quedan al margen de esta libertad pública. Es el caso de las páginas dedicadas al —comercio electrónicoll, pero también de esas otras que prestan diversos servicios telemáticos como, por ejemplo, -gestiones bancariasll o, incluso, portales de instituciones públicas" (p. 55).

20 El Tribunal Supremo de Justicia de Venezuela ha reconocido esta vertiente de la libertad de información, como derecho al acceso a la información por parte de individuos y colectividades, con ocasión de la sentencia 1013, en el caso del derecho a réplica de Elías Santana (expediente $n$. ${ }^{\circ}$ 00-2760), en la cual se sentó: "el accionante pretende hacer valer a su vez el derecho a la información imparcial, previsto en el artículo 58 de la Carta Fundamental, a favor del colectivo nacional, ... desde esta Sala ratificar el criterio asentado en sentencia del 30 de junio de 2000 (caso: Defensoría del Pueblo), según el cual esta Sala es competente para conocer de las acciones destinadas a ventilar los derechos e intereses difusos y colectivos, motivo por el cual esta Sala ratifica su competencia .... Se trata de dos derechos diferentes, uno dirigido a garantizar la expresión de las ideas u opiniones, y otro, en beneficio de los ciudadanos, constituido por el derecho de ser informados de manera oportuna, veraz e imparcial y censura, por los medios de comunicación, ya que el artículo 58 se refiere a la comunicación. Es en relación con la información comunicacional que surge el derecho a la réplica y a la rectificación, como un derecho de los ciudadanos ante los medios de comunicación en general. La doble fórmula de libertad individual y colectiva queda asentada aquí, sin lugar a dudas, como jurisprudencia nacional. Esta premisa también tiene validez en el Derecho español, donde las opiniones del Tribunal Constitucional en materia de libertad informativa han dejado en claro la posible exigibilidad conjunta de acceso o de difusión en cabeza de entidades empresariales o asociativas como ocurrió recientemente con el caso interpuesto por la Federación de Asociaciones de la Prensa de España y la Asociación de Fotoperiodistas y Reporteros de la Comunidad Autónoma de Madrid, a quienes el Tc les reconoce en su fallo 'el derecho de los recurrentes a comunicar libremente información veraz por cualquier medio de difusión' (sTC 159/2005, de 20 de junio de 2005). Si se le hubiese considerado un derecho exclusivamente individual o subjetivo, la Corte habría invalidado la solicitud incoada de manera colectiva a nombre de las referidas organizaciones. Esta dualidad de derecho individual y libertad pública la identifica muy bien el mexicano Ernesto Villanueva: 'Se puede afirmar que si bien es cierto que el sujeto activo de esta libertad puede ser, en estricto sentido, cualquier individuo, también lo es que generalmente se delega en los periodistas, quienes encuentran en esta libertad el fundamento más importante para el ejercicio de su profesión. De manera correlativa, el sujeto pasivo de la información es la colectividad”' (1998, p. 28). 
acceso a la información de carácter público, en posesión de los organismos estatales, en virtud de la destinación que se debe dar a dicha información, y por constituir por lo demás un elemento de transparencia en la gestión, excepto que exista alguna razón legítima que permita negar tal acceso, la cual debe justificarse en la protección del interés colectivo ${ }^{21}$ (seguridad nacional, protección de los derechos de terceros, etc.). No obstante, la libertad de información también comprende la obligación que tienen los Estados de dar publicidad y de difundir la información pública que sea de interés para la colectividad. En este aspecto cobra nuevamente importancia la utilización de las Tıc, ${ }^{22}$ puesto que constituyen un soporte material de singular relevancia para transmitir información pública, mediante las estrategias de gobierno electrónico. ${ }^{23}$

21 Una de las primeras medidas legislativas en este sentido se encuentra en la Real Ordenanza sobre Libertad de Prensa, dictada en Suecia en 1766, que recogió los postulados básicos sobre este tema y expresó el derecho de acceso de los ciudadanos suecos a la información oficial, lo cual la convierte en la norma pionera en cuanto al acceso a la información pública.

22 Recientemente la Asamblea Nacional venezolana aprobó la Ley de Infogobierno (originalmente denominada Ley de Tecnologías de la Información), que regula la utilización, con carácter obligatorio, de las TIC por parte de todos los entes públicos, en la divulgación de sus actividades. Aparte, la norma en cuestión establece la obligación preferente de utilizar software libre (o software de código abierto, por encima del software propietario o software con licencia), disposición que afecta el principio de neutralidad tecnológica según el cual las normas que regulen aspectos tecnológicos no deben pronunciarse a favor o en contra de una determinada tecnología, hecho que ha suscitado no pocas críticas.

23 En este ámbito, las RSı han venido cobrando particular relevancia, por cuanto los gobiernos están utilizándolas como medios para transmitir informaciones, vincularse con los ciudadanos, recibir quejas o denuncias, o para hacer anuncios o difundir elementos que pueden tener incidencia en la gestión pública. Es particularmente conocido que el presidente norteamericano Barack Obama se ha distinguido por el intenso uso de la red social Twitter, al igual que otros mandatarios de diferentes latitudes y niveles, para hacer anuncios de interés público o comunicarse con sus ciudadanos en mayor o menor grado, como sería el caso del Alcalde de Bogotá, Gustavo Petro, y en Venezuela el expresidente Hugo Chávez y el actual mandatario, Nicolás Maduro.
No cabe duda que el acceso a la información pública relevante constituye un derecho humano protegido internacionalmente, al estar tradicionalmente incluido dentro del derecho a la libertad de expresión y las prerrogativas de buscar y recibir información. ${ }^{24}$ La efectividad de este derecho se logra mediante la consagración de normas que garanticen el acceso a la información, de tal suerte que se consagre el principio general de máxima publicidad, ${ }^{25}$ que se contrapone a la opacidad en la gestión administrativa pública; de igual modo se precisa que las normas determinen procedimientos claros para regular el acceso a la información, así como la consagración taxativa de las excepciones a la publicidad de la información (conceptos de seguridad nacional, secretos oficiales, carácter reservado de ciertas informaciones, etc.). ${ }^{26}$

24 De acuerdo con el principio $\mathrm{n} .^{\circ} 1$ de la Declaración sobre la libertad de comunicación en Internet, del Consejo de Europa, de fecha 28 de mayo de 2003: "Los Estados miembros no han de colocar restricciones a los contenidos en Internet que vayan más allá de las aplicadas a otros medios de difusión de contenidos."

25 En el ámbito latinoamericano existen, como ejemplo, las siguientes leyes: La Ley peruana de Transparencia y Acceso a la Información Pública del 2002 (Ley n. ${ }^{\circ}$ 27806); la Ley Federal de Transparencia y Acceso a la Información Pública Gubernamental de México, del 2003, reformada en el 2007; La Ley Orgánica de Transparencia y Acceso a la Información Pública de Ecuador, del año 2004; la Ley de Acceso a la Información Pública de Nicaragua, del año 2007; la Ley General de Libre Acceso a la Información Pública Dominicana, de 2004; la Ley chilena de Transparencia de la Función Pública y Acceso a la Información de la Administración del Estado, de 2008.

26 De acuerdo con Mendel (2003), "Está empezando a surgir un tercer aspecto del derecho de acceso a la información: el derecho a la verdad. Dicho derecho se refiere a la obligación de los Estados de asegurar que los individuos conozcan la verdad respecto de casos serios de violaciones a derechos humanos, así como de otras situaciones sociales extremas, tales como un desastre ferroviario, como una epidemia. En dichos casos, no es suficiente que las autoridades permitan el acceso a sus archivos, ni que den publicidad a documentos claves que estén en su poder. Le incumbe al Estado asegurar que dicha situación sea completamente investigada y que los resultados de la misma se hagan públicos." 
La libertad de información incide sobre los denominados 'hechos noticiables', que se refieren a aquella información que sea relevante o de interés para la colectividad en general; no así con respecto al derecho a la intimidad, que constituye un límite a dicha libertad. No obstante, este límite es difuso, por cuanto no siempre es clara la distinción de qué elementos pertenecen a la esfera pública y cuáles a la privada, sobre todo si tomamos en consideración, por ejemplo, la vida privada de un funcionario público, de cuya honestidad y recato personal, depende la administración de los dineros públicos. ${ }^{27}$ Es por ello que los derechos a la intimidad y a la información están en una permanente vinculación entre aparentes opuestos, que en muchos casos varía, según el régimen político de cada país, y según lo abierta o no de una determinada sociedad. Por otra parte, se precisa establecer qué tipo de información es de acceso público y cuál no, toda vez que los funcionarios del Estado tienen la obligación de informar al ciudadano, ${ }^{28}$ y los administrados tienen derecho a dirigir toda clase de solicitudes o peticiones a la administración (derecho de petición), ${ }^{29}$ así como a ser

27 Urbina Serjant (2006) apunta que: "Ha empezado a tomar cuerpo en Venezuela, tal como ocurre en otras latitudes (verbigracia, España), la tendencia a otorgarle preeminencia al derecho a la información en casos en los que se involucren aspectos de la vida privada de funcionarios estatales de jerarquía, cuando la reserva oculta situaciones que afectan su desempeño público. Se legitima, entonces, la importancia fundamental de un derecho de todos frente a la relatividad excepcional de un derecho esencialmente subjetivo. Esto constituye un giro interesante en la aplicación del principio jurídico 'primus inter pares', empleado en la resolución de conflictos de legalidad entre derechos, que al menos en la doctrina, poseen similar relevancia" (pp. 62-63).

28 En tal sentido, la última parte del artículo 57 de la Constitución venezolana, establece: "Se prohíbe la censura a los funcionarios públicos o funcionarias públicas para dar cuenta de los asuntos bajo sus responsabilidades."

29 Este derecho aparece así consagrado en el artículo 51 de la Constitución venezolana: "Toda persona tiene el derecho de representar o dirigir peti- informados sobre el destino de sus solicitudes o recursos (derecho de respuesta). ${ }^{30}$ Por otra parte, el ejercicio del derecho a la información precisa por su propia naturaleza que se le garantice al ciudadano el derecho de acceso a esta, lo cual en el caso venezolano encuentra su concreción en la consagración del derecho a la innovación tecnológica, y la contribución al acceso universal a la información. ${ }^{31}$

ciones ante cualquier autoridad, funcionario público o funcionaria pública sobre los asuntos que sean de la competencia de éstos o éstas, y de obtener oportuna y adecuada respuesta. Quienes violen este derecho serán sancionados o sancionadas conforme a la ley, pudiendo ser destituidos o destituidas del cargo respectivo."

$30 \mathrm{El}$ artículo 143 de la Constitución venezolana establece: "Los ciudadanos y ciudadanas tienen derecho a ser informados e informadas oportuna y verazmente por la Administración Pública, sobre el estado de las actuaciones en que estén directamente interesados e interesadas, y a conocer las resoluciones definitivas que se adopten sobre el particular. Asimismo, tienen acceso a los archivos y registros administrativos, sin perjuicio de los límites aceptables dentro de una sociedad democrática en materias relativas a seguridad interior y exterior, a investigación criminal y a la intimidad de la vida privada, de conformidad con la ley que regule la materia de clasificación de documentos de contenido confidencial o secreto. No se permitirá censura alguna a los funcionarios públicos o funcionarias públicas que informen sobre asuntos bajo su responsabilidad."

31 El derecho a la innovación tecnológica está establecido en el artículo 110: "El Estado reconocerá el interés público de la ciencia, la tecnología, el conocimiento, la innovación y sus aplicaciones y los servicios de información necesarios por ser instrumentos fundamentales para el desarrollo económico, social y político del país, así como para la seguridad y soberanía nacional. Para el fomento y desarrollo de esas actividades, el Estado destinará recursos suficientes y creará el sistema nacional de ciencia y tecnología de acuerdo con la ley. El sector privado deberá aportar recursos para las mismas. El Estado garantizará el cumplimiento de los principios éticos y legales que deben regir las actividades de investigación científica, humanística y tecnológica. La ley determinará los modos y medios para dar cumplimiento a esta garantía." $Y$ con respecto al acceso a la información, la Constitución prevé el papel de los medios de comunicación social y la función del Estado, al determinar en el artículo 108: "Los medios de comunicación social, públicos y privados, deben contribuir a la formación ciudadana. El Estado garantizará servicios públicos de radio, televisión y redes de bibliotecas y de informática, con el fin de permitir el acceso universal a la información. Los centros educativos deben incorporar el conocimiento y aplicación de las nuevas tecnologías, de sus innovaciones, según los requisitos que establezca la ley." 


\section{Derecho a la información y privacidad}

Según Nogueira-Alcalá (2000), el derecho a la privacidad "consiste en el respeto del derecho a la vida privada de la persona y su familia, la cual queda excluida del conocimiento público y de las intromisiones de terceros, salvo autorización del afectado, lo cual permite salvaguardar una calidad básica de la vida humana" (p. 87); esta privacidad tiene como límite la ejecución de acciones que tengan repercusión sobre la esfera de las demás personas, cuando dichas acciones tengan un carácter antijurídico. Suele existir una tensión esencial entre la libertad de información y el derecho a la vida privada o derecho a la intimidad, ${ }^{32}$ puesto que este último tiene por finalidad la protección jurídica de una manifestación de la personalidad del ser humano, en su dimensión individual, ${ }^{33}$ que no obstante tiene interés para la sociedad en su conjunto en el sentido de procurar el bienestar de cada

32 La Constitución de la República Bolivariana de Venezuela establece en su artículo 60: "Toda persona tiene derecho a la protección de su honor, vida privada, intimidad, propia imagen, confidencialidad y reputación. La ley limitará el uso de la informática para garantizar el honor y la intimidad personal y familiar de los ciudadanos y ciudadanas y el pleno ejercicio de sus derechos." De allí que la protección del derecho a la intimidad personal constituye un límite del derecho a la información, pero también el artículo en referencia establece limitaciones respecto a la posibilidad de utilizar la informática como elemento potencialmente vulnerador de la privacidad de las personas (disposición inspirada en la Constitución española de 1978), a la vez que abrió la puerta para el desarrollo de legislación que contiene normas protectoras en la materia, tales como la Ley Especial contra Delitos Informáticos de 1991

33 Delpiazzo (2007) refiere con respecto a la evolución histórica del derecho a la intimidad, que: "es habitual señalar como hito fundamental en su perfilamiento, el clásico 'right to be alone' (1890), es decir, el derecho a ser dejado solo, o a ser dejado en paz, o a no ser importunado. Este concepto de 'privacy' apuntó básicamente a una protección jurídica contra la publicidad de actos o datos personales puestos en conocimiento del público sin noticia o permiso de la persona afectada. Posteriormente, dicho concepto se extendió para abarcar el derecho de los individuos, grupos o instituciones para determinar por sí mismos cuándo, cómo y con qué extensión puede ser comunicada a terceros la información acerca de aquéllos" (p. 130). uno de sus miembros; mientras que el derecho a la información tiene una clarísima dimensión social, por cuanto de este derivan beneficios que recaen sobre todo el grupo social.

El derecho a la intimidad ha evolucionado paulatinamente desde una consideración negativa, en el sentido garantista de impedir injerencias externas en las esfera íntima del ser humano, hacia una consideración positiva, desde la segunda parte del siglo XX en que se extendió la privacidad como un presupuesto para el ejercicio de otros derechos conexos, que poseen una clara proyección social e incluso económica, de manera que se protege no solo la esfera patrimonial que representa la privacidad sino también la dignidad y los derechos fundamentales del ser humano.

Entonces, queda claro que el derecho a la información no constituye un derecho irrestricto, sino que, por el contrario, está sometido a limitaciones derivadas de la aplicación de los principios constitucionales y de las disposiciones legales que salvaguardan derechos de los particulares. De allí que tradicionalmente se le reconozca a la información periodística una dimensión de servicio público, y que a los medios informativos se les exija estar al servicio de la población como conjunto, de lo cual emana su responsabilidad social, con las cargas y responsabilidades ulteriores que pudieran corresponderles de acuerdo con el ordenamiento jurídico de los países, teniendo como límites el respeto por ciertas personas (niños, adolescentes) y la emisión de mensajes que inciten a la violencia, entre otros. 
En cuanto a la relación entre la libertad de opinión e información y el derecho a la privacidad y a la honra, y los conflictos que se producen como consecuencia de los principios aplicables, ${ }^{34}$ Nogueira-Alcalá (2000, pp. 54-72) considera que se debe distinguir: A) En primer término si estamos en presencia del derecho a la libertad de información o de opinión, puesto que la primera constituye una exteriorización del pensamiento no susceptible de probarse científicamente, que se expresa mediante juicios de valor, los cuales responden a consideraciones de carácter subjetivo y dependen de los intereses, formación, valores, etc., de quien emite la opinión; ${ }^{35}$ mientras que la información consiste en la comunicación informativa de hechos y sucesos que ocurren en la realidad. ${ }^{36}$ De manera que cuando la libertad

34 El Tribunal Supremo de Justicia de Venezuela, en la sentencia 1013, ha sentado que: "En el conflicto entre la libertad de expresión e información y los derechos de la personalidad, el juez tiene que ponderar los derechos en conflicto, dándole un valor prevalente a los derechos a la libertad de expresión e información en su colisión con los derechos de personalidad, también fundamentales, siempre que aquellos se refieran a hechos o personas con relevancia pública, o estén destinados a la formación y existencia de una opinión pública libre, o no vacíen de contenido a los derechos de la personalidad, o dichas libertades se ejecuten conforme a su naturaleza y función constitucional, o si se trata de información, que ella sea veraz. Corresponderá a la jurisprudencia en cada caso realizar la ponderación y analizar los conceptos de relevancia pública y veracidad de la información."

35 Frecuentemente en las diatribas de opinión que se generan en el discurso político, la crítica se basa fundamentalmente en juicios de valor y no en declaraciones sustentadas en hechos, por lo que en muchos casos es muy difícil demostrar la veracidad de las declaraciones, puesto que los juicios de valor no admiten prueba.

36 En los últimos años se dio una polémica interesante en Chile, por cuenta de una persona que se sintió agraviada por un editorial del diario El Mercurio, de Santiago, y pretendió que se rectificara dicha opinión editorial. La Corte Suprema de ese país sentó el criterio conforme al cual, las opiniones pueden ser rectificadas solo en el caso que se fundamenten en hechos falsos, en consecuencia el derecho a la réplica se refiere solo a la información y no a la opinión. Establece el fallo referido, que "en principio no es razonable ni admisible sostener que las opiniones vertidas en los medios de difusión sean susceptibles de rectificación o aclaración. En la más estricta lógica no puede atribuirse a la crítica el carácter de falsa. Se puede convenir o discrepar de las opiniones, de los puntos de vista, pero en principio no resulta lógica ni jurídicamente admisible la pretensión de de información entre en conflicto con otros derechos o intereses de relevancia social, deben evaluarse las restricciones que puedan derivarse de dicho conflicto, cuidando que no se afecten los elementos esenciales que componen la libertad de información, dada la importancia que tiene desde el punto de vista institucional la consideración de dicha libertad. De acuerdo con el artículo 13 de la Convención Americana de Derechos Humanos, lo que eventualmente podría legitimar una intervención del Estado sería el hecho de que constituya una amenaza para la seguridad nacional, se afecte el orden público, o la salud o moral pública. B) Debe considerarse (i) si la información es de relevancia pública, condición que depende de la importancia intrínseca de los hechos en sí mismos considerados, o de la necesidad de que su conocimiento sea público; (ii) el carácter de la persona afectada, es decir, si se trata de una figura pública o no. ${ }^{37}$ Si se trata de información que no resulta públicamente relevante, debe prevalecer el derecho a la privacidad y honra personal. Ahora bien, si la noticia es de relevancia pública pero afecta a una persona sin mayor notoriedad pública,

rectificar tales juicios... [concluyendo que] la facultad de las personas de emitir opiniones y realizar una crítica acerba de los agentes y órganos estatales (gobierno, administración, parlamento, tribunales de justicia), es inherente al régimen democrático".

37 Se estima que una persona tiene el carácter de figura pública cuando es ampliamente conocida en una determinada sociedad, o cuando se ha involucrado voluntariamente en actividades de interés público, o se ha relacionado con una controversia de carácter institucional. De allí que los casos en que las personas se involucran voluntariamente en asuntos públicos, como sería el caso de los cargos de elección popular, o en el desempeño de altas funciones públicas, lógicamente implican una suerte de 'renuncia tácita' a cierto grado de protección del derecho a la intimidad y privacidad personales, por cuanto sus actuaciones, ejecutorias, actividades, relaciones, etc., van a estar sometidas a constante escrutinio por parte de la opinión pública. Estas consideraciones variarán sensiblemente según la consideración de la sociedad de que se trate, y de lo que resulte básicamente aceptable para dicha sociedad. 
la posible lesión del honor debe ceder ante la importancia de la información (Nogueira-Alcalá, 2000, p. 71). C) El derecho al honor prevalece sobre la libertad de expresión cuando este se ejerce abusivamente, haciendo uso de insultos innecesarios o apelativos formalmente injuriosos en cualquier contexto, ${ }^{38}$ en aquellos casos en que la información veraz de ideas y opiniones resulten innecesarias e incompatibles con la dignidad de la persona. ${ }^{39}$

Es claro que la crítica a la actuación de las figuras públicas resulta esencial dentro de las sociedades democráticas, lo cual prevé la necesidad de fomentar la tolerancia y el pluralismo en las ideas. Al mismo tiempo, las personas sometidas

38 Resulta conveniente precisar la relación que tiene la libertad de expresión con las denominadas 'leyes de desacato', es decir, aquellas donde se ofenda la dignidad de un funcionario público. Al respecto, la Comisión Interamericana de Derechos Humanos en su Informe Anual correspondiente al año 1994 (capítulo V), manifestó que dichas leyes son "incompatibles con el artículo 13 de la Convención Americana de los Derechos Humanos porque reprimen la libertad de expresión necesaria para el debido funcionamiento de una sociedad democrática, y que las leyes de desacato que todavía persisten en algunos países del hemisferio, no constituyen una restricción ilegítima de la libertad de expresión y no son necesarias para asegurar el orden público en una sociedad democrática, de allí que recomienda su derogación o adecuación a los instrumentos internacionales". El informe en cuestión plantea que "la aplicación de las leyes de desacato para proteger el honor de los funcionarios públicos que actúan en carácter oficial les otorga injustificadamente un derecho a la protección del que no disponen los demás integrantes de la sociedad... Si se considera que los funcionarios públicos que actúan en carácter oficial son, a todos los efectos, el gobierno, es entonces precisamente el derecho de los individuos y de la ciudadanía criticar y escrutar las acciones y actitudes de esos funcionarios en lo que atañe a la función pública... al proteger a los funcionarios públicos contra expresiones difamantes, las leyes de desacato establecen una estructura que, en última instancia, protegen al propio gobierno de las críticas." El informe concluye recomendando a los "Estados miembros de la Organización de Estados Americanos, en cuyos ordenamientos jurídicos existan estas leyes o leyes similares, derogarlas o reformarlas con el objeto de adecuarlas a los instrumentos internacionales, y a las obligaciones que a través de ellos han adquirido, armonizando de esa manera sus legislaciones con los tratados en materia de derechos humanos".

39 La tendencia internacional apunta hacia el reconocimiento de la doctrina del actual malice, que determina la aplicación de requisitos sumamente exigentes para la procedencia de demandas por difamación o injurias, cuando estas sean en contra de funcionarios públicos. al constante escrutinio público por razón de las funciones públicas que desempeñan, pueden tener un acceso constante a los medios de comunicación, lo cual les facilita, al tiempo, poder efectuar las aclaraciones pertinentes en cada caso. Es por ello que resulta razonable en estos casos una disminución de la protección del derecho a la honra y al honor de quienes gocen de notoriedad desde el punto de vista público, concretamente cuando las informaciones guarden relación con el ejercicio de la función pública que ejercen, o con los valores o desempeño que de estas personas se espera, con el objeto de garantizar una mayor transparencia en el ejercicio del poder en un Estado democrático, sin perjuicio de las responsabilidades ulteriores que pudieran corresponderle a las personas que vulneren la privacidad y el honor de dichos funcionarios.

Con respecto a la evolución de las tic y su relación con el derecho a la intimidad, Delpiazzo (2007) estima que:

La irrupción de la informática primero y de la telemática después, como resultante de su encuentro con las telecomunicaciones, ha replanteado la cuestión del derecho a la intimidad en atención al riesgo que para la persona implica la estructuración de grandes bancos de datos de carácter personal, y particularmente la potencialidad del entrecruzamiento de información contenida en ellos (p. 131).

El desarrollo de las TIC, sin duda, es positivo desde múltiples puntos de vista, sin embargo ello no implica bajar la guardia frente a unos derechos individuales que encuentran su razón 
eficiente y última en la libertad. De allí que el derecho a la intimidad y el secreto de las comunicaciones sean derechos internacionalmente protegidos. De hecho, se considera que la intimidad constituye un elemento fundamental para el desarrollo humano y para la realización de la libertad. ${ }^{40}$ Este derecho a la intimidad se encuentra garantizado en la Constitución Española, que en su texto lo acompaña del derecho al honor, intimidad familiar y propia imagen. ${ }^{41}$ La intimidad permite vedar el acceso a las otras personas, la cual por lo demás pertenece al patrimonio personal de los seres humanos y comprende elementos difíciles de definir, pero que involucran un amplio número de facultades y particularidades. ${ }^{42}$

Por otra parte, la mayoría de las constituciones del mundo protegen el secreto de la correspondencia, que se entiende extendido a las comunicaciones telegráficas, telefónicas, es decir, a las comunicaciones a distancia o telecomunicaciones, que por lo demás se caracterizan por el concepto que tienen las personas de que estas son privadas y que lo comunicado es secreto. Ahora bien, para garantizar dicho secre-

40 Desde este punto de vista, el control de la información relevante sobre la persona, que se encuentra contenida en bases de datos, ha dado paso al denominado 'derecho a la autodeterminación informativa', al cual nos referiremos más adelante, puesto que el derecho a la vida privada se proyecta en el ámbito de los registros que sobre las personas existan en bases de datos manuales y electrónicas.

41 Artículo 18.1. de la Constitución española: "Se garantiza el derecho al honor, a la intimidad personal y familiar y a la propia imagen."

42 La Constitución venezolana en su artículo 60 protege el honor, la vida privada, la intimidad, la propia imagen, la confidencialidad y reputación, e incorpora además la protección acerca del uso de la informática como elemento de vulneración de la privacidad, lo cual se debe adminicular, por lo demás, con la protección de la inviolabilidad de las comunicaciones privadas, establecida en el artículo 48. to el medio técnico empleado debe asegurar la existencia de no vulneración razonable de este, aspecto que motivó la distinción entre comunicaciones por canal cerrado y abierto. Resulta conveniente precisar que el secreto en las comunicaciones es independiente de que el contenido de la comunicación tenga carácter íntimo, y que no abarca solo el contenido de las comunicaciones, sino todas las circunstancias que la rodean, como identidad de los comunicantes y momento en que se realizan.

Ahora bien, los derechos mencionados no tienen un carácter absoluto. En opinión de RocaJunyent y Torralba (2002) "el precepto constitucional (español) parte de la base de que en ciertos casos el derecho al secreto de las comunicaciones ha de ceder frente a valores superiores y que la resolución judicial es, a su vez, una garantía para la no extensión indiscriminada de dicha noción de "valores superiores" (p. 188). De donde se puede limitar el derecho por parte de la acción de los jueces, que por lo demás debe ampararse en un precepto legal concreto que establezca las condiciones en que puede dictarse tal resolución, vale decir, en aquellos casos en que se autorice la interceptación de las comunicaciones privadas, cuando se busque evitar la comisión de un delito, como está establecido en Venezuela en la Ley de Privacidad de las Comunicaciones, de 1991.

Esta protección se refiere fundamentalmente a las injerencias por parte de los poderes públicos, pero la tendencia es a extender la protección a los casos de actuación de los particulares y al ámbito de la Internet, por interpretación ex- 
tensiva de los preceptos indicados. ${ }^{43}$ Se deben precisar algunas manifestaciones concretas de la privacidad de las comunicaciones, que guardan relación con los nuevos medios de comunicaciones telemáticas, y la consideración del secreto que le resulta aplicable.

Existen casos donde se evidencia la protección del secreto de las comunicaciones como manifestación de la protección del derecho a la intimidad. Ejemplo de ello es el correo electrónico de los trabajadores de las empresas y demás organizaciones públicas y privadas, en su consideración de hasta qué punto la información en él contenida forma parte de la esfera privada del empleado o del empleador, dado que las comunicaciones de los sistemas de correo electrónico están amparadas por el secreto de las comunicaciones. Al efecto se debería distinguir si el correo electrónico se utiliza desde las instalaciones de la organización, mediante los sistemas de esta y si corresponde a una cuenta de correo suministrada por la empresa, caso en el cual la información pertenecería al patrono, mientras que si el correo pertenece a una cuenta privada del trabajador, pero el servicio es utilizado desde el sistema del patrono, habría que considerar toda una serie de factores. ${ }^{44}$ Desde

43 Serrano (2002) estima que "El contenido del derecho se expresa en la libertad y el secreto de toda comunicación, no descarta el precepto ningún medio, todos los sofisticados instrumentos que la técnica puede ir creando, pero se refiere en especial a las comunicaciones clásicas: correspondencia epistolar (comunicación postal), telegráfica y telefónica” ( $p$. 373).

44 Ahora bien, las soluciones legales son diversas. Si bien Gran Bretaña ha legislado en contra de la protección del secreto del correo electrónico del trabajador, Francia y Alemania son proclives a defender dicha protección. No obstante, en ocasiones el secreto de las comunicaciones puede chocar con la potestad de vigilancia y control del empresario, a pesar de lo cual no se justifica la injerencia sin ningún tipo de control. una perspectiva crítica, llevando el tema al ámbito local, en Venezuela se han presentado en los últimos años algunos hechos que ponen en crisis ese principio nominal de protección de la privacidad de las comunicaciones, como la evidente falta de cumplimiento y respeto por parte de distintos organismos, y lo que es más grave, de importantes funcionarios gubernamentales que interfieren indebidamente y sin autorización judicial alguna, los sistemas de comunicaciones privados. ${ }^{45}$ Ahora bien, respecto de las cuentas de correo electrónico abiertas por los patronos para las funciones propias del ámbito laboral, pienso que no podemos generalizar, y llegar al acuerdo que esta debería ser utilizada exclusivamente para fines intracorporativos, lo cual es difícil de establecer de una manera absoluta y limitante, mientras que si se trata de una cuenta de correo personal del trabajador, utilizada fuera del ámbito del trabajo, lejos de la esfera de ejercicio de la prestación de servicios, debe estar completamente fuera del alcance e influencia del patrono.

\section{REDES SOCIALES Y EL EJERCICIO DEL DERECHO A LA INFORMACIÓN Y LA LIBERTAD DE EXPRESIÓN}

Las RSI comprenden plataformas creadas para intercambiar información, experiencias e intereses y generar espacios de convivencia entre los miembros de las comunidades virtuales que las integran, bajo condiciones similares y distintas

\footnotetext{
45 V. gr. caso de los generales en pantaletas, y de los videos y grabaciones de comunicaciones privadas divulgados por funcionarios en los medios de comunicación social.
} 
categorías de usuarios. La importancia y rápido crecimiento de las redes sociales, así como el explosivo crecimiento del número de usuarios, no es lo único que determina el interés mundial en estas, ${ }^{46}$ sino factores como su utilización en diferentes ámbitos, por ejemplo en las campañas políticas; ${ }^{47}$ en la promoción de movimientos sociales; ${ }^{48}$ como elemento para la vinculación ciudadana, para la obtención de información, para el establecimiento de comunicación próxima entre personas distantes, para expresar gustos e intereses, y sobre todo para la generación e intercambio de contenidos.

Conviene puntualizar que dentro de los atractivos que las personas encuentran en las RSI, y

\footnotetext{
46 Este interés mundial por la incidencia que las Rsı están teniendo en los más diversos aspectos de la vida del hombre, queda en evidencia, por ejemplo, en el Dictamen del Comité Económico y Social Europeo sobre Repercusión de las redes sociales de comunicación e interacción en el ciudadano/consumidor, que estableció entre otras cosas resaltantes, que "El CESE reconoce la importancia cultural, política y social de las redes sociales de comunicación en Internet (RSC) como instrumento de comunicación e interacción entre las personas, en el marco del ejercicio del derecho fundamental a la libertad de expresión. Al mismo tiempo, el CESE toma nota del interés económico asociado al desarrollo de las Rsc, en concreto su potencial para actividades de comunicación comercial y de mercadotecnia de diversos tipos (Unión Europea, 2010).
}

47 La campaña para la elección presidencial de Barack Obama en los Estados Unidos, en el año 2008, empleó intensivamente las redes sociales como Twitter y Facebook, no solo para hacer promoción y propaganda, sino además, para recaudar fondos, y para establecer vínculos con los electores. En su campaña para la reelección en el año 2012, se ratificó el uso de las RSI, intensificando y diversificando su uso mediante la segmentación y categorización de los usuarios, para "personalizar" el mensaje a los votantes, con la finalidad de establecer vínculos más cercanos con ellos.

48 Ambientalistas, de protestas sociales y ciudadanas. Este elemento se puso particularmente de manifiesto con las protestas en el año 2010 en Irán, tras las elecciones, así como los movimientos sociales y políticos en países como Túnez y Egipto, durante el año 2011 (por solo citar dos casos), que determinaron cambios en su sistema político, a pesar de que en ellos impera la censura y el control político sobre los medios de comunicación. En estos como en otros casos los ciudadanos han encontrado en las redes sociales canales para la expresión y difusión de información acerca de la realidad interna, y lograron utilizarlas como medio para convocar manifestaciones y para dar a conocer los desmanes cometidos por las autoridades. que han determinado en parte su éxito, están según Parra Castrillón (2010), “Aspectos como la presencia transcultural o la omnipresencia [que] hacen que las redes sociales se comprometan como nodos productores y consumidores de información" (p. 194). Esto, sumado a la posibilidad de compartir contenidos multimedia, las convierte en herramientas increíblemente poderosas para la vinculación humana. Estas transformaciones en la forma de comunicarnos, según Díaz Gandasegui (2011) ha hecho que "Las redes sociales se convierten en paradigma del hipertexto, en el que la palabra escrita, la imagen y el material audiovisual consiguen mantener a sus usuarios informados y entretenidos, fusionando así a los medios de comunicación masivos y personales, de entretenimiento y prácticos" (p. 2). En consecuencia, los integrantes de las redes sociales encuentran en ellas un espacio que les permite concentrarse, vincularse en virtud de sus intereses y gustos, así como crear y compartir contenidos, y lo más importante, la segmentación de las personas de acuerdo con sus particularidades.

Las RSI son el reflejo de una sociedad imbricada en los fenómenos de la conectividad propia de las nuevas tecnologías de la información y las comunicaciones, con los aspectos altamente positivos que dicha realidad representa, como son por ejemplo el incremento de la participación, la mayor posibilidad de comunicación, el caudal casi infinito de información y la posibilidad de unir a las personas independientemente de las fronteras geográficas y políticas, pero también con los problemas derivados de la preservación de la privacidad del individuo, la 
posibilidad de comisión de delitos por vía electrónica y la falta de confianza en la veracidad de las informaciones.

Fundamentalmente, las RSI se constituyen en la plataforma establecida para el intercambio de información, elemento fundamental para las relaciones económicas y sociales dentro de la sociedad tecnificada, por cuanto el acceso a la información significa control y poder. Sin embargo, uno de los mayores problemas a la hora de analizar las redes sociales, al igual que sucede con otros fenómenos sociales y culturales generados por la aparición y desarrollo de la tecnología, es que se encuentra en plena evolución y cuando se quiere estudiar el fenómeno, este ya ha cambiado.

Las RSI tienen una dimensión humana, que irradia desde la individualidad de la persona hacia la vinculación social con sus congéneres, a través del intercambio de informaciones, opiniones y contenidos. Pueden tener un carácter general, como sería el caso de Facebook, Google + o Twitter; especializadas por tipo de contenidos, como Instagram (imágenes), Blavin (notas de voz), Youtube (videos), Slideshare (presentaciones), Menéame (enlaces); profesionales como Linkedln; o con recomendaciones sobre compras, sitios de interés, ubicación de personas afines o sitios mediante sistemas de geolocalización (GPS), restaurantes, turismo y un amplísimo ámbito de aplicaciones.

No cabe duda de que las RSI tienen un papel relevante en la posibilidad de que los ciudadanos ejerzan el derecho a la información en su do- ble dimensión (derecho a informar y a ser informado), pues por un lado les permiten obtener información de forma instantánea, a partir de fuentes provenientes de todo el mundo, y por otro juegan un importante papel como medio de expresión de los intereses, deseos y expectativas de los usuarios-ciudadanos, así como para el desarrollo del periodismo entre personas del común que reportan las actividades y sucesos que ocurren en la realidad. Esto ha sido particularmente apreciable en los casos de tragedias naturales, sucesos políticos (como los del Medio Oriente desde el 2011), entre otros.

Pero si bien las RSI son un medio propicio para la manifestación de las opiniones personales, que sin embargo tiene aspectos propios y distintivos de otros medios electrónicos de difusión de información, como por ejemplo los correos electrónicos, las comunicaciones que circulan por ellas se encuentran protegidas claramente por el secreto de las comunicaciones, y las web visitadas amparadas por el derecho a la intimidad, a pesar de las implicaciones propias que impiden la total asimilación a dichos elementos. Así por ejemplo, si analizamos RSI como Facebook y Twitter, vemos que nos permiten intercambiar no solo opiniones o informaciones, sino enrutar la comunicación hacia otras páginas web, así como escritos, imágenes, videos, programas, etc., protegidos alternativamente por la normativa de propiedad industrial y de derechos de autor, y que implican igualmente la intimidad personal, el derecho a la protección de los datos personales y a la autodeterminación informativa, entre otros. 
A lo anterior se une que ante la naturaleza expansiva de las Rsı, la mayoría de los usuarios se consideran amparados por una falsa sensación de "intimidad", que los lleva a sentirse menos coartados para exponer juicios de valor. Algunos autores consideran que puede producirse justamente el fenómeno contrario, dentro de la denominada "espiral del silencio", ${ }^{49}$ según la cual una persona tiene menos posibilidades de expresar su opinión sobre un determinado tema si siente que está en minoría o afronta el peligro de ser víctima de represalias o de aislamiento. El advenimiento de los medios electrónicos en general, y de las Rsı en particular, ha hecho que la realidad cambie en virtud de la revalorización del empoderamiento del ciudadano frente a los grandes medios de difusión masivos, y pone en cuestionamiento esta interesante teoría y su aplicación a las RSı.

El poder comunicativo de estas plataformas deviene de lo que para una persona representa intervenir en una red social y hallar allí a otros con quienes compartir sus intereses, preocupaciones o necesidades, y romper el aislamiento que caracteriza a muchos en las sociedades contemporáneas, bien por la imposibilidad de establecer lazos permanentes, bien por el hecho de vivir en grandes conglomerados humanos donde, curiosamente, el ritmo acelerado de la vida restringe las oportunidades para compartir y comunicarse efectivamente. Frente a esta realidad, las redes sociales ofrecen alternativas, toda vez que según Parra Castrillón (2010):

49 Esta teoría fue propuesta por la politóloga alemana Elisabeth NoelleNeumann en su libro La espiral del silencio. Opinión pública: nuestra piel social, publicado en 1977. son medios para la instantaneidad, la actuación en tiempo real, el deleite por superar las distancias, el encantamiento producido por tener cerca en cualquier momento a los suyos. Estas redes emergen como una posibilidad para el establecimiento de relaciones sociales y contratos entre personas que comparten intereses y necesidades. 0 sea, Internet deja en escena canales para las necesidades de comunicación de los cibernautas, quienes pueden integrarse a comunidades especiales, fundar otras, ensancharlas y relacionarlas con ideales e identidades individuales y comunes (p. 198).

Como ya se comentó, uno de los aspectos que hacen de estas plataformas herramientas tan poderosas, es el hecho de poder segmentar las personas y contactos en virtud de los intereses, gustos, características, etc., lo que crea una categorización, especificación y sofisticación de herramientas y aplicaciones, es decir, una personalización y adaptación a las características de cada usuario.

Las nuevas realidades propias de las RSI hacen que las personas participen en la formación de la opinión pública de una forma más interactiva, puesto que se ha transformado no solo la manera en que se transmite la información, sino la relación emisor-receptor, dado que el propio ciudadano es emisor de los hechos y de las opiniones que considere necesario emitir, desde cualquier lugar y en cualquier momento. Las RSI constituyen, además, espacios para la generación de contenidos, al tiempo que canales para la difusión de información en la sociedad y en los medios tradicionales, que dejan de ofrecer información "cerrada y procesada" para alimen- 
tarse con las opiniones y aportes multimedia de los ciudadanos que reportan eventos de interés desde su teléfono móvil, o comparten un video en Youtube o imágenes en Instagram, en una nueva dimensión que apunta hacia la 'democratización de la información', ${ }^{50}$ puesto que son los usuarios quienes deciden cómo y dónde informarse, de qué manera participar, qué tan activamente hacerlo y con quiénes. Todo esto de acuerdo con la libre elección de cada individuo.

Otra particularidad interesante de las RSI es que la ductilidad para segmentar y organizar la información conforme a los gustos e intereses de los usuarios ha llevado a los medios de comunicación tradicionales, como prensa escrita, radio y televisión, a resignarse a perder protagonismo, o a tratar de adaptarse para presentar los contenidos de forma más dinámica e interactiva, y a utilizar precisamente las RSI como medio efectivo para vincularse con la audiencia, desarroIlando aplicaciones móviles para hacer frente a la migración que se está produciendo hacia los medios que generan contenidos exclusivamente por Internet. ${ }^{51}$

50 Ramón Fernández (2011) opina que "La web 2.0 y a través de ella, las redes sociales, ha originado la democratización de los medios haciendo que cualquier persona tenga las mismas posibilidades de publicar noticias que un periódico tradicional. Hay grupos de personas que crean blogs que tienen más visitas que cualquier periódico on line. La reducción de los costes de difusión de la información, así como el acceso cuándo y cómo queremos, hace que podamos tener nuestra emisora de radio on line, nuestro periódico on line, canal de vídeos... Sin embargo, esa libertad de acceso tiene como contrapartida que el aumento de la producción de la información también provoca que esta información llegue segmentada al usuario: sólo va a ser informado de lo que aparezca en la red social, pero no de toda la información producida. Ello no es propio de las redes sociales, sino también de cualquier medio de información que no sea digital, ya que la información en papel o en radio o televisión está también fraccionada por quienes insertan los contenidos en los soportes difusores de información" (p. 165).

51 Para Ramón Fernández (2011) “La web 2.0 implica una evolución, ya que pasamos de ser lectores de la información a ser protagonistas de la
Ahora bien, tomando en consideración que la cantidad de personas que intervienen en las RSI tiende a crecer exponencialmente, resulta perfectamente previsible que también constituyan terreno fértil para ser utilizadas con fines no siempre alineados con la ética, e incluso abiertamente contrarios a las leyes y a las buenas costumbres.

Moya (2003) estima que "Nada humano es hoy extraño a Internet. La Red no es más que un mundo dentro de otro. En la Red, por tanto, convive todo lo bueno y lo malo que la capacidad humana puede imaginar y comunicar" ( $p$. 97). De allí que las RSı puedan ser utilizadas bien para difundir contenidos nocivos o peligrosos, ${ }^{52}$ o bien para la comisión de delitos. En el primer escenario encontramos, fundamentalmente, aquellos que: i) Incitan al odio (racial, religioso, etc.), ${ }^{53}$ ii) Hacen apología de ideas extremistas

\footnotetext{
información, ya que podemos publicar contenidos, opinar, etc. El usuario se convierte en el principal protagonista y crea la información que luego es compartida por otras personas que acceden a la misma web" (p. 169).
}

52 En Venezuela, la regulación de los contenidos que se cursan por medios radioeléctricos está establecida en la LRSRTVME, que inicialmente se aplicaba a los contenidos divulgados por los servicios de radio y televisión de señal abierta y a los servicios por suscripción. No obstante, en la reforma que entró en vigencia a comienzos del año 2011, se extendió su aplicación a los "medios electrónicos", sin definir la norma en cuestión qué debe entenderse por tales, por lo que en principio podría considerarse que su aplicación resultaría posible a las RSI y a los medios de difusión por Internet. Dentro de su normativa, destaca el artículo 27 que prohíbe la difusión de mensajes, que "Inciten o promuevan el odio y la intolerancia por razones religiosas, políticas, por diferencia de género, por racismo o xenofobia. 2. Inciten o promuevan y/o hagan apología al delito. 3. Constituyan propaganda de guerra. 4. Fomenten zozobra en la ciudadanía o alteren el orden público. 5. Desconozcan a las autoridades legítimamente constituidas. 6. Induzcan al homicidio. 7. Inciten o promuevan el incumplimiento del ordenamiento jurídico vigente."

53 Son destacados, y lamentablemente cada vez más frecuentes, los casos de utilización de RSI como Facebook y Twitter para incitar al odio y la exclusión (grupos neonazis que incitan al odio contra los judíos, negros y un largo etc.); al cyberbulling (ciberacoso o cibermatoneo) contra personas particularmente sensibles como, por ejemplo, adolescentes, y que en casos extremos han conducido incluso al suicidio, lo cual ha llamado la 
(fundamentalismos religiosos o políticos), iii) Incitan al desprecio a la dignidad humana (pornografía, información difamatoria o denigrante con respecto a las personas). En cuanto a la utilización para la comisión de conductas antijurídicas e ilícitas, sería el caso referirnos a la difusión de contenidos que: i) Afecten los derechos de niños y adolescentes (pornografía infantil, ${ }^{54}$ cyberbulling); ii) Resulten contrarios a la dignidad humana (incitación al odio, discriminación racial, religiosa o por causa de su orientación sexual); iii) Sean contrarios a la seguridad de los sistemas informáticos (sabotaje o daños a los sistemas informáticos); 55 iv) Atenten contra la protección de la intimidad; ${ }^{56} \mathrm{v}$ ) Atenten contra la protección de la reputación de las personas; ;7 vi) Amena-

atención de las autoridades y organizaciones a nivel mundial, acerca de la necesidad de establecer medidas que permitan detectar estas situaciones de forma temprana para proscribirlas.

54 La Ley Especial contra Delitos Informáticos (LECDI) venezolana, establece como delitos contra niños y adolescentes, los siguientes: difusión o exhibición de material pornográfico (art. 23), exhibición pornográfica de niños o adolescentes (art. 24).

55 La LECDI establece como delitos que atentan contra los sistemas que utilizan tecnologías de la información, los siguientes: acceso indebido (art. 6), sabotaje o daño a sistemas (art. 7), sabotaje o daño culposo (art. 8), acceso indebido o sabotaje a sistemas protegidos (art. 9), posesión de equipos (art. 10), espionaje informático (art. 11), falsificación de documento (art. 12). Conviene puntualizar que no se precisa que la actividad de los hackers tenga por finalidad necesariamente causar daños a los sistemas (crackers), o bien obtener beneficios de naturaleza económica para el agente o para un tercero, aun cuando en estos casos se consideran estas circunstancias como agravantes que, en consecuencia, incrementan la pena aplicable.

56 La LECDI establece como delitos que atentan contra la privacidad de las personas y de las comunicaciones, los siguientes: violación de la privacidad de la data o información de carácter personal (art. 20), violación de la privacidad de las comunicaciones (art. 21), revelación indebida de data o información de carácter personal (art. 22).

57 Son abundantes los ejemplos de casos en los que se han utilizado las RSI para denigrar personas e instituciones, afectando su reputación e, incluso, la dignidad. El Tribunal Supremo alemán se ocupó del caso de la red social "chuleta" (spickmich.de), en la cual los alumnos calificaban a los profesores, y una docente consideró que la difusión del resultado de la calificación era denigrante para ella. Ver sobre el tema, Klink (2011). cen la seguridad nacional (producción y distribución de sustancias estupefacientes o psicotrópicas ilegales, actividades terroristas, tráfico o elaboración de explosivos); vii) Atenten contra la protección de la propiedad intelectual. ${ }^{58}$

Así, ha sido frecuente que se utilicen las RSı para emitir comentarios o informaciones falsas, ${ }^{59}$ denigrantes o abiertamente delictivas, y resulta difícil determinar la falsedad, si han sido emitidas de mala fe, o si el propósito era obtener un beneficio económico en detrimento del sujeto a quien van dirigidas (personas, empresas, productos o servicios), ${ }^{60}$ cuestiones que tienen que resolverse mediante la determinación de las responsabilidades ulteriores en el ámbito civil o penal por conllevar una doble dimensión: la de las personas que emiten efectivamente los comentarios en referencia, y la de los responsables de las RSI. En ambos casos se deben establecer las normas y condiciones de uso, que permitan en la medida de lo posible evitar la difusión de contenidos abusivos y que garanticen, al tiempo, la salvaguarda de la libertad de

58 El artículo 24 de la LECDI consagra el delito de apropiación de propiedad intelectual, así: "El que sin autorización de su propietario y con el fin de obtener algún provecho económico, reproduzca, modifique, copie, distribuya o divulgue un software $u$ otra obra del intelecto que haya obtenido mediante el acceso a cualquier sistema que utilice tecnologías de información, será sancionado con prisión de uno a cinco años y multa de cien a quinientas unidades tributarias."

59 Son ampliamente conocidos, por ejemplo, los rumores acerca de la muerte de personajes famosos, que resultan completamente falsos y son posteriormente desmentidos.

60 Se debe tomar en consideración la diferencia esencial entre la difusión de informaciones falsas de carácter pernicioso, y la difusión de opiniones personales que puedan resultar igualmente negativas, por cuanto el tratamiento debería diferir en ambos casos, en cuanto a la posibilidad de aplicación del derecho a réplica o derecho a rectificación, según los casos. 
expresión, cuyo límite está determinado por la violación de los derechos de terceros. ${ }^{61}$

En el caso concreto de la legislación venezolana, el primer aparte del artículo 27 de la LRSRTVME establece la obligación para los 'proveedores de medios electrónicos' (expresión un tanto imprecisa, pero que se ha interpretado como extensible a los proveedores de contenidos en Internet, dentro de los cuales se encontrarían las RSI), de establecer mecanismos que permitan restringir la difusión de mensajes que inciten al odio, la intolerancia (racial, nacional, religiosa, de género), hagan apología del delito, inciten al homicidio o al desconocimiento de las autoridades legítimamente constituidas, ${ }^{62}$ hagan propaganda de guerra, promuevan el incumplimiento del ordenamiento jurídico vigente. ${ }^{63}$ Esta obligación debe actualizarse cada vez que sea

61 Hoy en día hablamos de "reputación digital", para referirnos "al prestigio o estima de una persona o marca en Internet. Un prestigio o estima que no depende de la persona física o jurídica afectada sino que la - fabricanll terceros a través de opiniones, experiencias, comentarios, etc. $Y$ es que es esa participación de terceros en la conformación de la identidad y reputación digital la base sobre la que se asienta la presente comunicación ante la necesidad de tener que hacer uso del llamado derecho de rectificación ante contenidos o informaciones inexactas y cuya divulgación pueda causar perjuicios a los sujetos afectados" (Torres, 2011, p. 378)

62 Esta mención tan imprecisa podría interpretarse de manera muy diversa, por cuanto las posiciones que pueden presentarse en el debate político, pueden incluir el proferir opiniones particulares, a favor o en contra de personas, ideas o instituciones, lo cual es perfectamente normal en todo sistema democrático; por lo que la aplicación inadecuada por parte de funcionario, puede resultar contraproducente, y en el fondo promover en los medios electrónicos la autocensura.

63 La forma amplia en que están redactadas las prohibiciones en la LRSTVME, en cuanto a la difusión de mensajes, aplicable a los servicios de radio, televisión, difusión por suscripción y medios electrónicos, es sumamente imprecisa. Por ejemplo, la incitación al desconocimiento del ordenamiento jurídico vigente puede resultar contrario a la libertad de expresión, necesaria en todo régimen democrático, dado que el emitir opiniones relativas al desacuerdo de un ciudadano (o grupo de ciudadanos) respecto de determinada norma, ley, ordenanza, podría subsumirse dentro de esta prohibición y determinar responsabilidad al medio de comunicación, RSI, etc. requerida por parte de la Comisión Nacional de Telecomunicaciones (Conatel). ${ }^{64}$ La responsabilidad por la difusión de los mensajes prohibidos le corresponderá a los "proveedores de medios electrónicos", respecto de la información y los contenidos, cuando: "hayan originado la transmisión, modificado los datos, seleccionado a los destinatarios o no hayan limitado el acceso a estos, en atención al requerimiento efectuado por los órganos con competencia en la materia" (segundo aparte del artículo 27 de la LRSRTVME). Nótese que en estos casos, la responsabilidad se transfiere del emisor del mensaje, a quien presta la plataforma electrónica, vale decir, el medio en Internet o la RSI. ${ }^{65}$

Las prácticas ilegales que se suelen realizar mediante las RSI comprenden fundamentalmente: A) La utilización de perfiles falsos con la intención de difundir información falsa o denigrante respecto de personas, empresas, productos 0 servicios, ${ }^{66}$ suplantando la identidad de los verdaderos usuarios (phishing), ${ }^{67}$ o bien con la fina-

64 El incumplimiento de esta obligación es sancionado, conforme lo establece el $2^{\circ}$ parágrafo del art. 27 de la LRSRTVME, así: "los proveedores de medios electrónicos que no atiendan las solicitudes realizadas por los órganos competentes a los fines de dar cumplimiento a las disposiciones de la presente Ley, serán sancionados con multa de hasta un cuatro por ciento $(4 \%)$ de los ingresos brutos generados en el ejercicio fiscal inmediatamente anterior a aquél en el cual se cometió la infracción.”

65 La sanción aplicable en este caso está establecida en el 1er. parágrafo del art. 27 de la LRSRTVME, que reza: "los responsables de los medios electrónicos serán sancionados con multa desde cincuenta hasta doscientos Unidades Tributarias (50 hasta 200 U.T.), cuando violen cualquiera de las prohibiciones contenidas en el presente artículo."

66 Las RSı facilitan la difusión de contenidos que pueden afectar la reputación o al buen nombre de profesionales, marcas corporativas, empresas o particulares. Contenidos respecto de los cuales es muy difícil controlar, rectificar o determinar responsabilidad, cuando se desconoce su autoría.

67 Son bastante conocidos los casos de personas que usurpan las cuentas de Twitter de políticos, escritores y artistas para difundir información 
lidad de realizar chantajes o cometer delitos de cualquier índole, aprovechando la facilidad de crear perfiles y la carencia de mecanismos de seguridad robustos para verificar la información suministrada por los usuarios. B) Sustracción de información personal, la cual se ve facilitada por el hecho de que los usuarios de las RSI suelen colocar datos en muchos casos sensibles, así como imágenes, información acerca de gustos, actividades, intereses y estatus socioeconómico, que puede ser utilizada por personas inescrupulosas con fines contrarios a las leyes e incluso en muchos casos para cometer delitos. ${ }^{68}$ Lo anterior se ve favorecido, por lo demás, por el desarrollo de programas de minería de datos (data minning), que facilitan la creación de perfiles en Internet mediante la combinación de información contenida en bases de datos electrónicas de diversa naturaleza. Estas prácticas se dificultan en la medida en que, por una

falsa o sesgada, con finalidades de diversa índole, desde política hasta de carácter comercial. Fueron muy notorios estos casos en Venezuela, respecto de las cuentas de personalidades como el escritor Leonardo Padrón, del canal de noticias Globovisión o del periódico Tal Cual, entre otros, durante el año 2012.

68 La publicación por parte de los usuarios de información personal, que es compartida en las RSI, hace nacer una nueva realidad, una suerte de "extimidad" (para contraponerla a la intimidad propia de la esfera personal del individuo), que cuestiona la esfera de protección del derecho a la intimidad, y determina que: "Toda esta actividad de exposición pública del desarrollo de la vida cotidiana, que en otros momentos quedaba limitada a un circulo reducido de conocidos, se extiende, en el mejor de los casos, al grupo de - amigos - que se ha decidido agregar. Sin embargo, esto no es siempre así. Por un lado, y como han puesto de manifiesto tanto los responsables de la Agencia de Protección de Datos (año 2009), como los integrantes de la 30 Conferencia Internacional de Autoridades de Protección de Datos y Privacidad, el usuario medio desconoce que, en realidad, su perfil no resulta tan privado como pueda parecer, pues la mayoría de redes configuran los perfiles como públicos por defecto, lo que supone que, salvo que se haya activado la herramienta de cierre del mismo, no sólo sus amigosll (esto es, aquellas personas que ha aceptado en su página) pueden verlo, sino que también los amigos de sus amigos, o incluso toda la comunidad (como ocurre, por ejemplo, en Tuenti)" (Lloria García, 2011, p. 471). parte, se optimicen las políticas de prestación de servicios, especialmente en cuanto a la privacidad de la información suministrada, y por la otra, haya una mayor conciencia por parte de los usuarios, de la importancia de restringir y mantener niveles adecuados de protección de la información de carácter sensible que puede ser suministrada en las RSI. C) Propagación de malware o programas informáticos maliciosos, que pueden captar información privada y difundirla a terceros no autorizados.

Ahora bien, se debe advertir que la forma como las personas se comunican y vinculan mediante las RSI varían significativamente según el tipo de red social de que se trate. Por ejemplo, en las RSI especializadas, corrientemente las personas se organizan de acuerdo con intereses especiales o mediante características específicas que tienen en común, lo cual determina el carácter y tipo de vinculación. En las redes generales, como por ejemplo Facebook y Twitter -las más empleadas en Occidente-, funciona así: A) La comunicación en Twitter tiene como elemento esencial la inmediatez y brevedad de la información, por cuanto es remitida de usuarios a quienes los suscriptores "siguen", de tal suerte que el usuario de la red es quien elige de quién quiere recibir información. Los emisores pueden enviar mensajes no superiores a 140 caracteres (tweet, similares a un mensaje corto de texto o sms) a quienes han elegido seguirlos. Los receptores (followers) reciben esos mensajes, si bien también pueden convertirse en emisores. La sencillez y tamaño reducido de los tweets hace que se le considere una red de "microblogging', que obliga a sintetizar el contenido 
de los mensajes. ${ }^{69}$ Su éxito estriba en lo multifacético y polivalente que resulta su plataforma, pues al contener mensajes de reducido tamaño se ha favorecido su uso mediante los teléfonos móviles (los tweets comprenden aproximadamente 20 palabras), y permiten crear, integrar e intercambiar información, ideas, localización de personas y múltiples aplicaciones de forma casi inmediata, aparte de contar con un motor de búsqueda (Twitter Search, que posibilita búsquedas actualizadas en tiempo real, sobre todos los tweets que se elaboran en el mundo, así como el establecimiento de un ranking de Ios temas relevantes (trending topics). Redondo (2010) destaca que: "Por su inmediatez, se convirtió pronto en una de las herramientas más importantes para informarse de forma anticipada, y fue uno de los medios más potentes en el Ilamado 'periodismo ciudadano'. Cualquiera podía tomar una foto de un acontecimiento y subirla de inmediato con un pequeño titular, o "retwittear (reenviar a sus contactos un twitt que acaba de leer), una noticia de última hora" (p. 46). B) Facebook es un espacio que favorece más el diálogo y responde al paradigma de usuarios registrados, quienes funcionan como "amigos", no "seguidores", que interactúan de una manera bidireccional, y que es más proclive al intercambio de contenidos multimedia. Aparte, esta red es más propicia para la interacción y manifestación de opiniones ('gusto' o ‘disgusto'), con eventos, ideas y contenidos; adicional-

69 Esparza (2010) opina que "el tráfico de información en estas redes... hace que su uso se haya convertido en un arte que combina la ya vieja tradición del chat con nuevas tendencias de mercadeo, divulgación viral de la información, periodismo ciudadano, exposición en medios e incluso tradicionales formas de etiqueta, reeditadas y adaptadas a los medios actuales de circulación de la información (pp. 21-22). mente, la plataforma de esta red permite la interacción mediante el chat y la videoconferencia, redactar notas y compartir contenidos y enlaces a páginas o recursos en la web, juegos, grupos de interés, así como toda una serie de aplicaciones que poseen gran utilidad desde el punto de vista del Comercio Electrónico en Internet.

\section{CONCLUSIÓN}

No cabe duda de que las RSı constituyen elementos para la participación y vinculación directa por parte del ciudadano. Esto determina que el posicionamiento de las personas frente a los medios y formas de vinculación y comunicación varíe, toda vez que de consumir pasivamente información se pasa a convertirse en entes generadores de información que se crea, modifica y posteriormente consume de una forma activa. Este protagonismo en la formación de la opinión pública, que se orienta hacia un proceso de desintermediación de la información, precisa la reconfiguración de conceptos tradicionales en materia de protección de datos personales, del derecho a la intimidad y a la vinculación con un amplio rango de derechos que pueden verse vulnerados por los hechos, noticias y opiniones que circulan por las RSI.

En cuanto al ejercicio de las libertades comunicacionales, es indudable el valor que las RSI cumplen como instrumentos de participación, de vinculación entre las personas, propios de la sociedad de la información. ${ }^{70}$ No obstante,

70 Aun cuando hay quien piensa que las RSı en particular, y los aparatos electrónicos, computadores personales, teléfonos móviles, computadoras 
el uso indiscriminado de las RSI, así como la utilización por parte de personas inescrupulosas de información de carácter personal, las hace susceptibles de ser utilizadas para cometer actos ilícitos, abusar de la intimidad de las personas y efectuar actos contrarios a la moral y a las buenas costumbres, por lo que cobran una relevancia inusitada las políticas de seguridad y privacidad que estas RSI aplican respecto de sus usuarios, y que permiten elevar los niveles de seguridad y de privacidad de la información suministrada. ${ }^{71}$ De igual modo, la elemental prudencia y sentido común deben primar en los usuarios en cuanto al sano manejo de estos instrumentos en su interacción con otras personas.

\section{Referencias}

Castells, M. (2006). La era de la información. Economía, sociedad y cultura (Sexta ed.). México: Siglo Veintiuno Editores.

Chavero, R. (2006). El reino de la intolerancia. El problema de la libertad de expresión en Venezuela. Caracas: Editorial Aequitas.

Delpiazzo, C. (2007). El derecho a la intimidad en el nuevo horizonte telecomunicativo. En

portátiles en general, sirven para 'acercar a los que están lejos, mientras se aleja a los que están cerca', en virtud del uso intensivo y a veces aislante que hacen las personas, al querer estar permanentemente conectadas a las redes informáticas.

71 Las políticas y normas de seguridad de las RSI, como por ejemplo Facebook, prohíben expresamente la realización de prácticas lesivas de intereses personales o comerciales de terceros y la realización de actos ilegales. La infracción de las normas hace que la Rsı pueda tomar medidas que conducen incluso a la inhabilitación de las cuentas o el bloqueo del material violatorio. Estas normas en muchos casos pueden resultar insuficientes, pero en todo caso necesarias.
M. Rico (Coord.), Derecho de las nuevas tecnologías. Buenos Aires: Ediciones La Rocca.

Díaz Gandasegui, V. (2011). Mitos y realidades de las redes sociales. Obtenido de isdfundacion: http://www.isdfundacion.org/publicaciones/revista/numeros/6/secciones/ tematica/07-mitos-realidades-redes-sociales.html, 2011

Escobar de la Serna, L. (1998). Derecho de la información. Madrid: Editorial Dykinson.

Esparza, D. (2010). Cómo twittear y no morir en el intento. Caracas: Ediciones Grijalbo.

Faúndez, H. (2004). Los límites de la libertad de expresión. México: Instituto de Investigaciones Jurídicas, UNAM.

Fernández, J. (2002). La modulación de la libertad de información en Internet. En M. Carbonell (Coord.), Derechos fundamentales y Estado. Memoria del VII Congreso Iberoamericano de Derecho Constitucional. México: Universidad Nacional Autónoma de México.

Grimalt, P. (2011). Responsabilidad civil por contenidos en la red: LSSICE y Ley de Prensa y responsabilidad civil por hecho ajeno. Obtenido de derechotics: http://www.derechotics.com/congresos/2010-libertades-y-20/elibro-elibertades-2010.

Klink, T. (2011). La actual posición del Tribunal Supremo alemán ante la libertad de expresión en la red, el caso de la "chuleta". Obtenido de http://www.derechotics.com/ 
congresos/2010-libertades-y-20/e-libro-elibertades-2010

Lloria García, P. (2011). Intimidad y redes sociales ¿cómo alcanzar la tutela penal? Obtenido de: http://www.derechotics.com/ congresos/2010-libertades-y-20/e-libro-elibertades

Mendel, T. (2003). Libertad de información: derecho humano protegido internacionalmente. Revista Derecho Comparado de la Información.

Moya, R. (2003). La libertad de expresión en la red Internet. Revista Chilena de Derecho Informático, (2), 89-106.

Nogueira Alcalá, H. (2000). El derecho a la información en el ámbito del derecho constitucional comparado en Iberoamérica y Estados Unidos. En J. Carpizo y M. Carbonell (Coords.), Derecho a la información y derechos humanos. México: Universidad Nacional Autónoma de México.

Novoa, E. (2001). Derecho a la vida privada y libertad de información. Un conflicto de derechos. (Sexta ed.). México: Siglo Veintiuno Editores.

Parra Castrillón, E. (2010). Las redes sociales de Internet: también dentro de los hábitos de los estudiantes universitarios. Obtenido de dialnet: http:// dialnet.unirioja.es/servlet/ fichero_articulo?codigo $=3417235 \&$ orden $=0$
Ramón Fernández, F. (2011). La red social como ejemplo de participación: casos y cuestiones. En, Libertades de expresión e información en Internet y las redes sociales: ejercicio, amenazas y garantías. Valencia: Universidad de Valencia. Obtenido de http://www.derechotics.com/congresos/2010-libertades-y-20/elibro-elibertades-2010

Redondo, J. (2010). Socialnets. Barcelona: Ediciones Península.

Roca-Junyent, M. y Torralba, E. (2002). Derecho a la intimidad: el secreto de las comunicaciones e Internet. En J. Cremades, M. Fernández-Ordóñez y R. Illescas (Coords.), Régimen Jurídico de Internet. Madrid: Editorial La Ley.

Rubio Núñez, R. (2011). Las redes sociales en las administraciones ¿Periodo de pruebas? Obtenido de: http://www.derechotics.com/ congresos/2010-libertades-y-20/e-libro-elibertades

Serrano, J. (2002). Comentario al artículo 18 de la CE. En Comentarios a la Constitución. Madrid: Civitas.

Teruel, G. (2011). El legislador y los riesgos para la libertad de expresión en Internet: notas sobre las garantías constitucionales de la libertad de expresión en la LSSICE y en la disposición final segunda del Proyecto de Ley de Economía Sostenible. Obtenido de derechotics: http://www.derechotics.com/ congresos/2010-libertades-y-20/e-libro-elibertades-2010 
Urbina Serjant, J. (2006). Nuevos rasgos del derecho a la información en Venezuela. Mérida: Universidad del Zulia, Ediciones del Vice Rectorado Académico.

Villanueva, E. (1998). Derecho comparado de la información. México: Universidad Iberoamericana. 